Article

\title{
A Novel Reverse Logistics Network Design Considering Multi-Level Investments for Facility Reconstruction with Environmental Considerations
}

\author{
Xuehong Gao $\mathbb{D}$ \\ Department of Industrial Engineering, Pusan National University, Busan 609-735, Korea; gao201608@gmail.com; \\ Tel.: +82-010-29369027
}

Received: 15 March 2019; Accepted: 8 May 2019; Published: 13 May 2019

\begin{abstract}
Reverse logistics is convincingly one of the most efficient solutions to reduce environmental pollution and waste of resources by capturing and recovering the values of the used products. Many studies have been developed for decision-making at tactical, practical, and operational levels of the reverse supply chain. However, many enterprises face a challenge that is how to design the reverse logistics networks into their existing forward logistics networks to account for both economic and environmental sustainability. In this case, it is necessary to design a novel reverse logistics network by reconstructing the facilities based on the existing forward logistics network. Multi-level investments are considered for facility reconstruction because more investment and more advanced remanufacturing technologies need to be applied to reduce the carbon emissions and improve facility capacities. Besides, uncertain elements include the demand for new products and return quantity of used products, making this problem challenging. To handle those uncertain elements, a bi-objective stochastic integer nonlinear programming model is proposed to facilitate this novel reverse logistics network design problem with economic and environmental objectives, where tactical decisions of facility locations, investment level choices, item flows, and vehicle assignments are involved. To show the applicability and computational efficiency of the proposed model, several numerical experiments with sensitivity analysis are provided. Finally, the trade-off between the profit and carbon emissions is presented and the sensitive analysis of changing several key input parameters is also discussed.
\end{abstract}

Keywords: carbon emissions; facility reconstruction; reverse logistics network; stochastic integer programming; sustainability

\section{Introduction}

Facing the increasing competitiveness of business and market globalization, firms have been focusing on the supply chain network design for a few decades. Usually, the supply chain network design involves suppliers of raw materials, production plants, distribution centers (warehouses), and customer zones. Supply chain management encompasses the planning and management of all activities involved in sourcing and procurement, conversion, and all logistics management activities [1]. Because it has been suggested by experts that $80 \%$ of supply chain cost is determined by facility locations and item flows among facilities, a better supply chain network should be strategically designed to reduce the cost [2-6].

In the last few decades, with a greater awareness of responsibility for the environment and the need to sustain profitability in a competitive market, the reverse logistics network design has become a key part of supply chain management, which has resulted in great interests in remanufacturing operations and the sustainability of logistics in supply chain management $[7,8]$. Reverse logistics, which is defined as the process of planning, implementing, and controlling the efficient and cost-effective flow of raw 
materials, in-process inventory, finished goods, and related information from the point of consumption to the point of origin for the purpose of recapturing value or proper disposal [9]. In reverse logistics, the used products (also referred to as end-of-life or end-of-use products) from customers are repaired and recovered back to the proper function [10-12] at remanufacturing plants. After that, the recovered products can be redelivered to the customer zones to be sold again.

In reverse logistics, the flow of used products is processed from the customer zones to remanufacturing plants and disposal centers via hybrid distribution centers [13]. In the supply chain network design, designing the reverse logistics network independently usually leads to a sub-optimal design with respect to the objectives of the whole supply chain $[14,15]$. Hence, the reverse logistics network should be designed with respect to the forward logistics network [16] to better balance the economic and environmental benefits. Besides, if the market demand holds steady, constructing additional facilities to recover the used products is also costly and unnecessary. Considering the higher infrastructure cost in the establishment of reverse logistics network independently $[17,18]$, the design of a reverse logistics network by reconstructing the existing facilities into hybrid processing facilities is an efficient solution to save cost and reduce carbon emissions as a result of sharing the base infrastructure [19]. Little research concerning facility reconstruction has been conducted in the past. Besides, to further reduce carbon emissions and improve environmental performance, higher investments are beneficial because more advanced remanufacturing technologies can be applied in a reverse logistics system $[20,21]$. A higher volume of used products can also be collected due to higher investments [22]. Hence, it is reasonable to consider multi-level investments in terms of technology selection and design for facility reconstruction so that the different remanufacturing technologies can be applied to balance the economic and environmental benefits. In addition, uncertainty is one of the most significant challenges in the design of the reverse logistics network, such as demand for new products and return quantity of used products. However, the literature integrating uncertain elements in the reverse logistics network design problems is still rare.

Against the backdrop of uncertainties, the aim of this study is to design a reverse logistics network by reconstructing the existing facilities into hybrid processing facilities under an uncertain environment, where the new and used products can be transported via these hybrid processing facilities. The main goal of this study is to formulate a bi-objective stochastic integer nonlinear programming model for this novel reverse logistics network design with objectives of maximization of the expected total profit and minimization of the expected total carbon emissions of the system. The trade-off between those two objectives is justified to support production, recovery, and disposal activities in reverse logistics network. Specifically, the main tasks of this study are to determine investment levels at facilities, item flows (i.e., raw materials, used products, and new products), and vehicle numbers of different types between facilities.

The remainder of this paper is organized as follows. Section 2 systematically reviews the previous studies that are related to mathematical programming models for the reverse logistics network design problems. Section 3 provides a description of the problem with concerns. In Section 4, a bi-objective stochastic integer nonlinear programming model is proposed to handle the novel reverse logistics network design problem. Then, computational results are presented and discussed in Section 5. Finally, Section 6 concludes this study, outlining its contributions and possible directions for future work.

\section{Literature Review}

In the last few decades, many attempts have been conducted to design the reverse logistics network. Here, the literature review is separated into two subsections. In the first subsection, some recent studies of reverse logistics network design models under uncertainty are reviewed. The second subsection summarizes some previous literature associated with carbon emissions in the design of reverse logistics networks. The studies considering facility reconstruction in reverse logistics network design are also reviewed in this subsection. 


\subsection{Reverse Logistics Network Design}

Within the last decade, reverse logistics network design has drawn the attention of researchers and firms due to the growing environmental concerns, legislation, corporate social responsibility, and sustainable competitiveness [23]. Prajapati, et al. [24] summarized the number of articles on reverse logistics in the journals with its H-index. The number is 84 from 2009 to 2011, 128 from 2012 to 2014, and 147 from 2015 to 2017, where the growing number of studies reflects the significance of this subject. Due to the popularity of generic reverse logistics network design, some recent literature about reverse logistics network design has been reviewed by many researchers. For instance, Pokharel and Mutha [25] investigated the development in research and practice in reverse logistics network design through content analysis of the published literature, which started from the collection of used products to the final output processing. Agrawal, et al. [23] presented a comprehensive review of the literature on reverse logistics network design issues, which filled the gap between the previous issues and outlined the future directions for research. However, they filed to outline the redesign of the reverse logistics network.

Most previous studies in this area have focused on the problem only in deterministic environments [26-28]. However, the main feature of reverse logistics network design is the high-level uncertainty inherent, which is one of the most important challenges in reverse logistics activities. Particularly, the uncertainties in the demand for new products and return quantity of used products are inescapable based on a review by Govindan, et al. [29]. Many studies have investigated various uncertain factors in reverse logistics through stochastic optimization models with different possible scenarios. Listeş and Dekker [30] presented a stochastic mixed-integer programming model for product recovery network design, which was extended to explicitly account for the demand and supply uncertainties. Salema, et al. [31] studied and designed a generic reverse logistics network to minimize the total cost. They considered capacity limits, multi-product management, and uncertain demand for the new products and return quantity of used products. Niknejad and Petrovic [7] developed a two-phase fuzzy mixed-integer optimization model for the inventory control and production planning problem in an integrated reverse logistics network under demand and return quantities uncertainties. Moghaddam [32] developed a fuzzy multi-objective mathematical model for designing a reverse logistics network, which captured several uncertain elements including customer demand, supplier capacity, and percentage of used products. Daaboul, et al. [33] proposed an integrated closed-loop product lifecycle management approach to design a reverse logistics network, which was divided into two processes. The first process involved environmental impacts of the potential reverse logistics networks, whereas the most appropriate reverse logistics network was selected in the second process. $\mathrm{Li}$, et al. [34] designed a multi-period multi-echelon reverse logistics network for multiple products to maximize the profit incurred in the recovery process, where the uncertain quantity and quality of used products from customers were considered.

Based on the above studies, within the scope of reverse logistics network design, the uncertainty is an inescapable feature that needs to be considered. However, the above studies neglect that the feature of carbon emissions is also an important part of the design of the reverse logistics network. In addition to the consideration of monetary objectives of commercial logistics, this study also considers the carbon emissions as an objective. Given various uncertain elements, the stochastic modeling approach has been widely utilized by many researchers to solve the reverse logistics network design problems $[23,35,36]$. Besides, many researchers have developed various single-objective optimization models by simply penalizing carbon emissions using carbon tax [37-39] and introducing it into the objective function, which is inappropriate because the carbon tax is very difficult to be determined. Different from previous studies, this study considers two objectives separately, namely (i) maximization of the total profit and (ii) minimization of the total carbon emissions. However, the methodology to design a reverse logistics network with those two objectives under uncertainty is still rare. Thus, there is a need to develop a bi-objective stochastic optimization model to better deal with carbon emissions under uncertainty. 


\subsection{Carbon Emissions and Facility Reconstruction in Reverse Logistics Network Design}

To emphasize the responsibility for environmental sustainability, the environmental impact (carbon emissions) needs to be considered as an objective in the design of the reverse logistics network. However, due to the difficulty in counting the carbon emissions, environmental impact is usually accounted through a proxy measure in the reverse logistics activities. Hence, many researchers have considered this objective in their reverse logistics network design problems. Kannan, et al. [40] proposed a mixed-integer linear programming model to minimize the total cost for a carbon footprint-based reverse logistics network design by monetizing and compositing carbon emissions $\left(\mathrm{CO}_{2}\right.$ footprint $)$ with the overall system cost. Diabat, et al. [41] presented a multi-echelon multi-commodity facility location problem to minimize the sum of fixed-facility location, transportation, and carbon emission costs for the closed-loop supply chain design, with a trading price of carbon emissions and a cost of procurement. Choudhary, et al. [37] presented a quantitative operational decision-making model for an integrated forward and reverse logistics network design by considering the carbon emissions. The model aimed to minimize both the total cost and the carbon footprint of the whole supply chain system. Yu and Solvang [21] proposed a multi-objective mixed-integer programming model for the design of a general reverse logistics network, which aimed to minimize the system operating cost and minimize the carbon emissions associated with the transportation and processing of used products. Guo, et al. [42] developed a two-stage integrated forward and reverse logistics network for food e-commerce enterprises under the environment of low-carbon emissions. The model aimed to minimize the overall cost of the system in the first stage and minimize the overall cost of the circulation-type distribution vehicle routing in the second stage. Zarbakhshnia, et al. [8] proposed a multi-objective mixed-integer linear programming model for designing and planning a green forward and reverse logistics network, whereby three objectives were considered: namely (i) minimization of the total cost; (ii) minimization of $\mathrm{CO}_{2}$ emissions; and (iii) minimize the number of machines in the production line. Xiao, et al. [43] proposed a mixed integer linear programming mathematical model for a design of four-tier reverse logistics network for end-of-life vehicles under carbon tax regulation. Obviously, the carbon emissions associated with transportation and production have been widely considered in the above studies. However, they neglect the fact that the carbon emissions also come from raw materials themselves [44], which also has a great influence on the item flows in the reverse logistics network. Besides, the above studies only consider the same item-based carbon-emission rate in the transportation process, which is also inappropriate. In the practical transportation process, different vehicle types are commonly rented to deliver the items between facilities [45], which results in different vehicle-based carbon emissions. Thus, different vehicle types need to be considered in the design of reverse logistics. In addition, the methodology suggested by Hickman, et al. [46] is used to calculate carbon emissions of different vehicle types and applied in this study.

In practice, many enterprises have faced such a problem that is how to redesign their existing supply chains and implement the related activities to improve environmental performance [47,48], for example the redesign of the reverse logistics network to recover the used products, such as containers and electronics (e.g., cylinders and cameras) [49-51]. It has been proven convincingly that the supply chain redesign with multi-purpose production plants (also referred to as hybrid processing production plants) is helpful for decision makers to decide where to introduce a new production process [49]. Feitó-Cespón, et al. [52] proposed a multi-objective stochastic optimization model to redesign the sustainable supply chain to recycle certain products. However, the hybrid processing production plant has never been considered in the reverse logistics network design. This is because it has been suggested that approximately $70 \%$ of global greenhouse gas emissions come from infrastructure construction and operations such as power plants, buildings, and transportation [53]. In addition, shared infrastructure can reduce carbon emissions by between 50 and 70 percent in a system [54]. Facility reconstruction needs to be considered so that the infrastructure can have shared use for reducing carbon emissions. To further reduce the carbon emissions and improve profit, multi-level investments for reconstructing 
facilities are considered because more advanced remanufacturing technologies can be applied in the reverse logistics system [20-22].

It has been suggested that designing the reverse logistics network independently may lead to sub-optimal performance [55], so the reverse logistics network design should be conducted with respect to the existing forward logistics network. To avoid the sub-optimality caused by the separate design of the reverse logistics network, facility reconstruction is considered as a solution to design the reverse logistics network based on the redesign of the existing forward logistics network [56], which is seldom studied before. Only Dai and Wang [57] designed a reverse logistics network on the basis of the existing forward logistics network, where the existing distribution centers were reconstructed for expansion to handle the recycling items. Considering the higher cost and carbon emission of infrastructure in the establishment of reverse logistics network independently $[17,18]$, the design of a reverse logistics network by reconstructing the existing facilities into hybrid processing facilities is an efficient solution to save cost and reduce carbon emissions as a result of sharing the base infrastructure [19]. In this study, specifically, both the hybrid processing production plants and hybrid processing distribution centers are necessary to be reconstructed while designing the reverse logistics network.

\subsection{Novelty and Contribution}

With respect to the previous studies, many efforts have been conducted for the reverse logistics network design under uncertainty. However, the literature considering carbon emissions in the design of the reverse logistics network is still rare. To avoid the sub-optimal design of a reverse logistics network, a novel reverse logistics network needs to be designed with respect to the existing forward logistics network. Besides, facility reconstruction, which reduces the infrastructure cost and carbon emissions [20-22], has never been considered in the design of reverse logistics network under the context of carbon emissions and uncertain environment. In addition, no previous studies consider multi-level investments to reconstruct facilities that make the design of the reverse logistics network more reliable and flexible. Those concerns make this reverse logistics network design problem more challenging.

To fill this research gap, the current study is conducted and the contribution can be summarized as follows. Firstly, a novel reverse logistics network design problem is presented by reconstructing the existing facilities into hybrid processing facilities with respect to the existing forward logistics network. Secondly, this study considers uncertain demand for new products, return quantity of used products, multi-level investments at facilities, and carbon emissions (caused by transportation, raw materials, and production process). Thirdly, to better model the reality, different vehicle types with different capacities and carbon-emission rates are used to deliver the items between facilities. Then, a bi-objective stochastic integer nonlinear programming model is proposed to model this reverse logistics network design problem, with the objectives of maximizing the total profit and minimizing the total carbon emissions. In addition, the weighted-sum methodology is applied to solve the proposed bi-objective stochastic optimization model. Finally, a numerical analysis is conducted to show the applicability and computational efficiency of the proposed model.

\section{Problem Description}

This section describes the novel reverse logistics network design problem by reconstructing the facilities based on the existing forward logistics network under the considerations of carbon emissions and an uncertain environment. In the forward logistics network, suppliers, production plants, distribution centers, and customer zones (retailers) are considered. Whereas the reverse logistics network comprises customer zones, collection centers, disposal centers, and recovery plants. In the design of the reverse logistics network, hybrid processing facilities are considered to save cost and reduce carbon emissions because of sharing material handling equipment and infrastructures. Hybrid distribution-collection (HDC) centers and hybrid production-recovery (HPR) plants can be built by reconstructing the existing distribution centers and production plants, respectively. Hence, 
the collection process can be performed at HDC centers, and the recovery process can be performed at HPR plants.

As illustrated in Figure 1, in the forward logistics network, the raw materials are shipped from suppliers to production plants and HPR plants, where the new products are produced. After the production process, these new products are shipped to customer zones to meet the demand of customers via distribution and HDC centers. In the reverse logistics network, at customer zones, the used products are inspected and sorted into two groups according to their quality levels: recovery and disposal. The used products with lower quality levels are shipped to disposal centers directly. The remaining used products are shipped to HPR plants for recovery via HDC centers. After the recovery activities, the recoverable products are redelivered to customer zones to be sold via distribution and HDC centers. The main problem in the design of the reverse logistics network is to choose the existing distribution centers and production plants that need to be reconstructed into HDC centers and HPR plants, respectively.

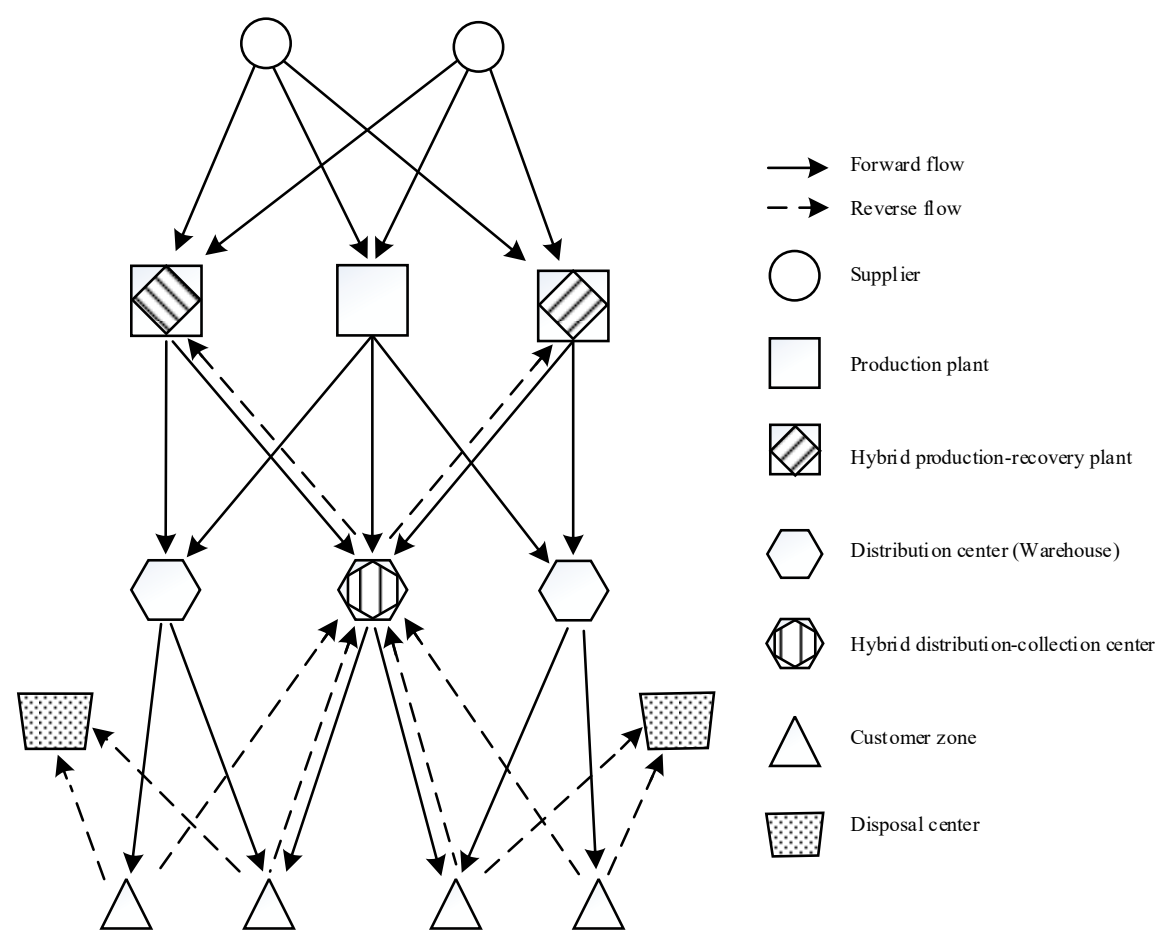

Figure 1. Reverse logistics network design based on the existing forward logistics network.

In the design of this novel reverse logistics network, the high-level inherent uncertainty makes the problem a big challenge. At customer zones, the uncertain demand for new products is inescapable because of market volatility. Whereas, in the reverse logistics network, the return quantity of used products is usually uncertain. To overcome the previously identified limitations, the uncertain elements are represented in terms of a number of discrete realizations of stochastic quantities that constitute distinct scenarios. For supply and demand at a customer zone, there is a set of scenarios $\Xi$. For a particular scenario $\xi \in \Xi$, there is a probability of occurrence $P(\xi)$, such that $P(\xi)>0$ and $\sum_{\xi \in \Xi} \mathrm{P}(\xi)=1$.

In addition to the uncertain elements in the design of the reverse logistics network, this study also considers the carbon emissions not only from the raw materials but also from the production and transportation processes. In the transportation process, carbon emissions caused by vehicles are considered. The methodology used to calculate carbon emissions comes from Hickman, et al. [46]. They consider carbon emission performances from different vehicle types. The functions of carbon emission rates depend on the average vehicle speed and a number of predefined parameters. For a given vehicle type with weight, the parameter values provided by Hickman, et al. [46] are adopted and the 
corresponding carbon emission $\left(\mathrm{CO}_{2}\right)$ factor can be obtained. Moreover, this study also considers the multi-level investments at facilities so that a more reliable reverse logistics network can be designed to further reduce total investment and carbon emissions.

On the whole, it is hoped that this study can provide great decision-making in the design of a novel reverse logistics network from the perspective of economic, environmental, and social sustainability. The objectives of this novel reverse logistics network design are to maximize the expected total profit and to minimize the expected total carbon emissions for the whole system. The total revenue consists of the income obtained from selling new products at customer zones and used products at disposal centers. The total cost comprises the multi-level investments at facilities (i.e., distribution centers, production plants, and disposal centers), purchase cost (i.e., raw materials and used products), production cost, recovery cost, and transportation cost. The carbon emissions come from the raw materials, production process, and transportation process.

Before the mathematical formulation is presented for the novel reverse logistics network design problem, some assumptions are provided:

- The forward logistics network with facilities is given. The HPR plants and HDC centers are selected from the existing production plants and distribution centers, respectively. The potential disposal center locations are known.

- The return rate of used products for recovery is given. The used products with lower quality levels are delivered to the disposal centers directly. The used products with higher quality levels can be recovered at HPR plants.

- The materials are sufficient at suppliers so that the demand at customer zones can be met. In addition, one unit of raw material is used to produce one new product.

- The carbon emissions of raw materials and production process are known. The carbon emissions of vehicles used in this study are predefined and suggested by Hickman, et al. [46].

\section{Stochastic Programming Model}

\subsection{Notations}

The proposed mathematical model uses the following notations.

\begin{tabular}{ll}
\hline Sets & \\
\hline $\mathcal{Z}$ & Set of customer zones, indexed by $z \in \mathcal{Z}$. \\
$\mathcal{C}$ & Set of distribution centers (potential HDC centers), indexed by $c \in \mathcal{C}$. \\
$\mathcal{B}$ & Set of potential disposal centers, indexed by $b \in \mathcal{B}$. \\
$\mathcal{P}$ & Set of production plants (potential HPR plants), indexed by $p \in \mathcal{P}$ \\
$\mathcal{L}$ & Set of investment levels, indexed by $l \in \mathcal{L}$. \\
$\mathcal{S}$ & Set of suppliers, indexed by $s \in \mathcal{S}$. \\
$\mathcal{T}$ & Set of vehicle types, indexed by $t \in \mathcal{T}$ \\
$\Xi$ & Set of scenarios, indexed by $\xi \in \Xi$. \\
\hline Parameters & \\
\hline$I B^{b l}$ & Cost of investment-level $l$ for opening disposal center $b$. \\
$I C^{c l}$ & Cost of investment-level $l$ for reconstructing HDC center $c$. \\
$I P^{p l}$ & Cost of investment-level $l$ for reconstructing HPR plant $p$. \\
$Q r^{s}$ & Quantity of raw materials at supplier $s$. \\
$S n^{c l}$ & Capacity of new products at distribution center $c$ under investment-level $l$. \\
$H n^{c l}$ & Capacity of new products at potential HDC center $c$ under investment-level $l$. \\
$D u^{c l}$ & Capacity of used products at potential HDC center $c$ under investment-level $l$. \\
$C r^{p l}$ & Capacity of raw materials at production plant $p$ under investment-level $l$. \\
$H r^{p l}$ & Capacity of raw materials at potential HPR plant $p$ under investment-level $l$. \\
\hline
\end{tabular}




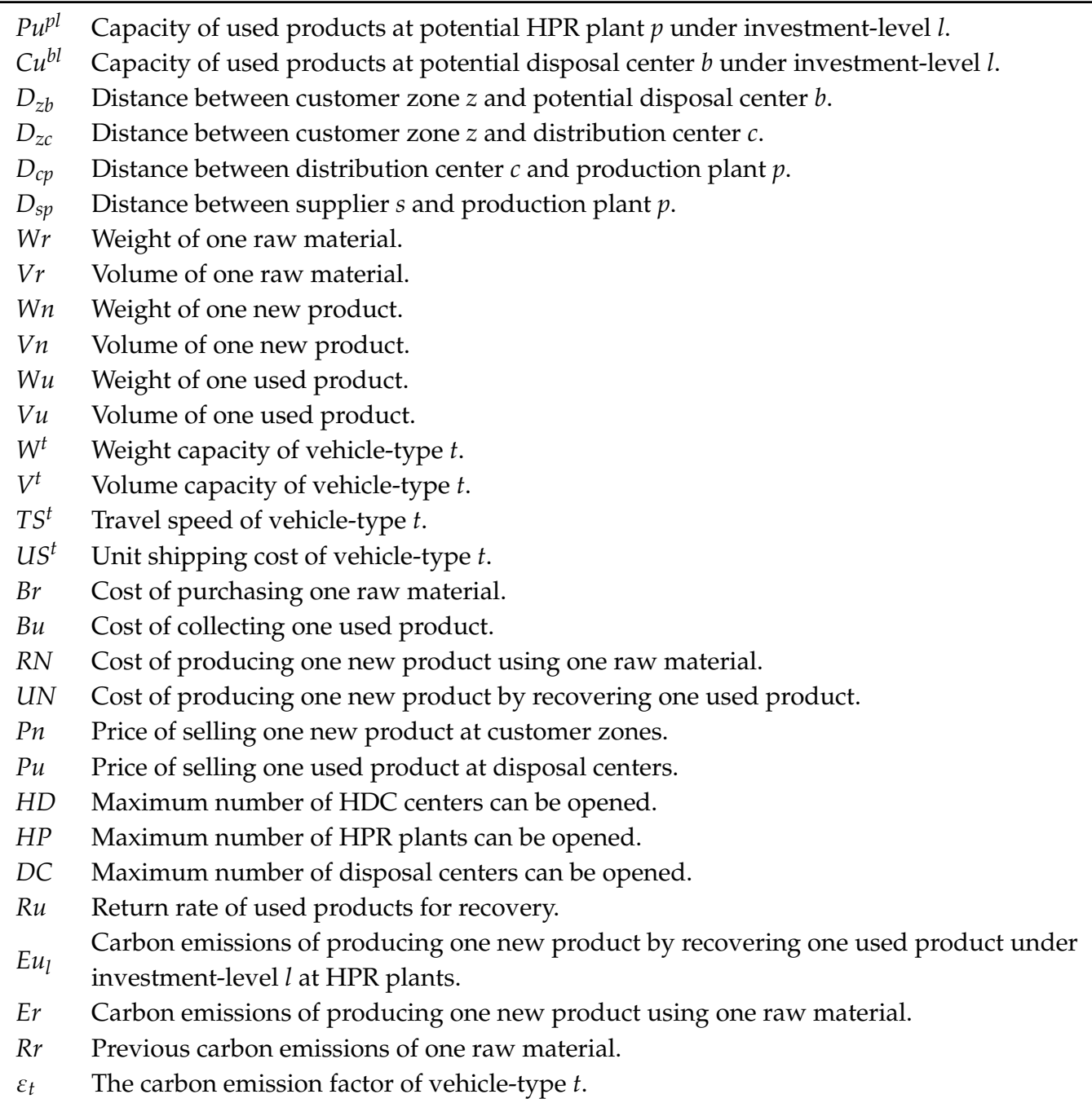

Stochastic parameters

$D^{z \xi} \quad$ Potential demand for new products at customer zone $z$ in scenario $\xi$.

$R^{z \xi} \quad$ Potential quantity of used products at customer zone $z$ in scenario $\xi$.

$P^{\xi} \quad$ Occurrence probability of scenario $\xi$.

Decision variables

$u a_{\xi}^{z b} \quad$ Quantity of used products shipped from customer zone $z$ to potential disposal center $b$ in scenario $\xi$.

$u p_{\xi}^{z c} \quad$ Quantity of used products shipped from customer zone $z$ to potential HDC center $c$ in scenario $\xi$.

$u q_{\xi}^{c p} \quad$ Quantity of used products shipped from potential HDC center $c$ to potential HPR plant $p$ in scenario $\xi$.

$r a_{\xi}^{s p} \quad$ Quantity of raw materials shipped from supplier $s$ to potential HPR plant $p$ in scenario $\xi$.

$n p_{\xi}^{p c} \quad$ Quantity of new products shipped from potential HPR plant $p$ to potential HDC center $c$ in scenario $\xi$.

$n q_{\xi}^{c z} \quad$ Quantity of new products shipped from potential HDC center $c$ to customer zone $z$ in scenario $\xi$.

$\varphi a_{t \xi}^{z b}$ Quantity of used products stored in vehicle-type $t$ from customer zone $z$ to disposal center $b$ in scenario $\xi$.

$\varphi p_{t \xi}^{z c}$ Quantity of used products stored in vehicle-type $t$ from customer zone $z$ to potential HDC center $c$ in scenario $\xi$.

$\varphi q_{t \xi}^{c p} \quad$ Quantity of used product stored in vehicle-type $t$ from potential HDC center $c$ to potential HPR plant $\varphi q_{t \xi} \quad p$ in scenario $\xi$.

$\varphi r_{t \xi}^{s p}$ Quantity of raw material stored in vehicle-type $t$ from supplier $s$ to potential HPR plant $p$ in scenario $\xi$.

$\varphi g^{p c}$ Quantity of new products stored in vehicle-type $t$ from potential HPR plant $p$ to potential HDC center $\varphi g_{t \xi} \quad c$ in scenario $\xi$. 


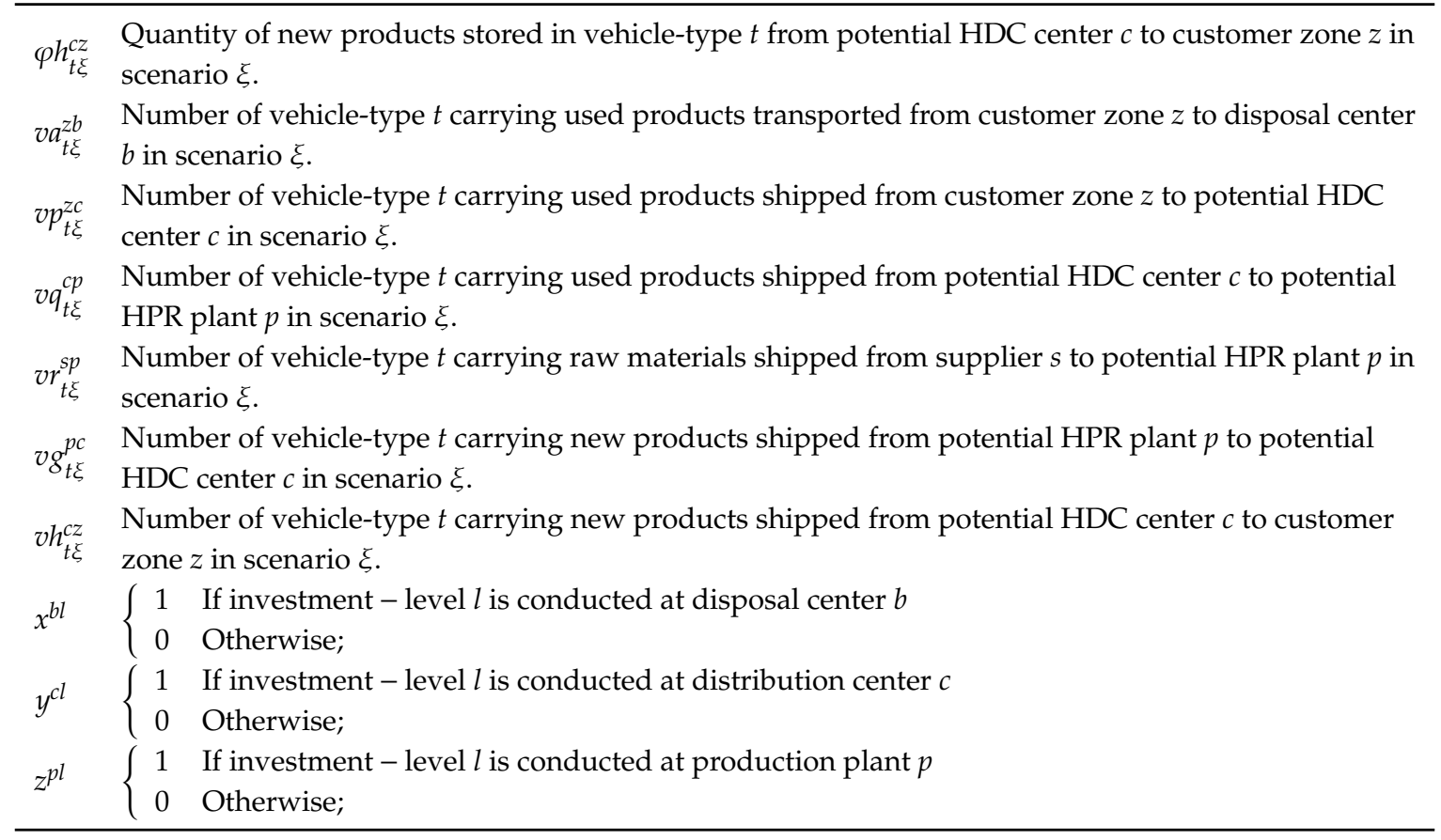

\subsection{Model Formulation}

In this study, the goals are to maximize the expected total profit for the whole system and to minimize the expected total carbon emissions so that the optimal disposal center locations, multi-level investments at facilities, and transportation strategy are determined. The model $\mathbb{P}$ is evaluated by the following two objective functions:

$$
\begin{array}{ll}
\mathbb{P}: & \\
& \operatorname{Max} \Psi_{1}=I N+I U-O F-O R-O U-O P-O T \\
& \operatorname{Min} \Psi_{2}=E R+E P+E T
\end{array}
$$

where $\Psi_{1}$ is the expected total profit and $\Psi_{2}$ is the expected total carbon emissions; IN is the income of selling new products at customer zones; $I U$ is the total income of selling used products at disposal centers; $O F$ is the investment at facilities (i.e., disposal centers, distribution centers, and production plants); $O R$ is the cost of purchasing raw materials from suppliers; $O U$ is the cost of purchasing used products at customer zones; $O P$ is the cost in the production process; $O T$ is the cost in the transportation process; $E R$ is the carbon emissions of raw materials; $E P$ is the carbon emissions in the production process; and $E T$ is the carbon emissions in the transportation process. The components can be calculated through the following formulas.

$$
\begin{gathered}
I N=\sum_{c \in \mathcal{C}} \sum_{z \in \mathcal{Z}} \sum_{\xi \in \Xi} P^{\xi} \cdot P n \cdot n q_{\xi}^{c z} \\
I U=\sum_{z \in \mathcal{Z}} \sum_{b \in \mathcal{B}} \sum_{\xi \in \Xi} P^{\xi} \cdot P u \cdot u a_{\xi}^{z b} \\
O F=\sum_{b \in \mathcal{B}} \sum_{l \in \mathcal{L}} I B^{b l} \cdot x^{b l}+\sum_{c \in C} \sum_{l \in \mathcal{L}} I C^{c l} \cdot y^{c l}+\sum_{p \in \mathcal{P}} \sum_{l \in \mathcal{L}} I P^{p l} \cdot z^{p l} \\
O R=\sum_{s \in \mathcal{S}} \sum_{p \in \mathcal{P}} \sum_{\xi \in \Xi} P^{\xi} \cdot B r \cdot r a_{\xi}^{s p}
\end{gathered}
$$




$$
\begin{aligned}
& O U=\sum_{z \in \mathcal{Z}} \sum_{c \in C} \sum_{\xi \in \Xi} P^{\xi} \cdot B u \cdot u p_{\xi}^{z c} \\
& O P=\sum_{s \in \mathcal{S}} \sum_{p \in \mathcal{P}} \sum_{\xi \in \Xi} P^{\xi} \cdot R N \cdot r a_{\xi}^{s p}+\sum_{c \in C} \sum_{p \in \mathcal{P}} \sum_{\xi \in \Xi} P^{\xi} \cdot R U \cdot u q_{\xi}^{c p} \\
& O T=\sum_{z \in \mathcal{Z}} \sum_{b \in \mathcal{B}} \sum_{t \in \mathcal{T}} \sum_{\xi \in \Xi} P^{\xi} \cdot\left(v a_{t \xi}^{z b} \cdot \frac{D_{z b}}{T S^{t}} \cdot U S^{t}\right)+\sum_{z \in \mathcal{Z}} \sum_{c \in C} \sum_{t \in \mathcal{T}} \sum_{\xi \in \Xi} P^{\xi} \cdot\left[\left(v p_{t \xi}^{z c}+v h_{t \xi}^{c z}\right) \cdot \frac{D_{z c}}{T S^{t}} \cdot U S^{t}\right] \\
& +\sum_{c \in C} \sum_{p \in \mathcal{P}} \sum_{t \in \mathcal{T}} \sum_{\xi \in \Xi} P^{\xi} \cdot\left[\left(v q_{t \xi}^{c p}+v g_{t \xi}^{p c}\right) \cdot \frac{D_{c p}}{T S^{t}} \cdot U S^{t}\right]+\sum_{s \in \mathcal{S}} \sum_{p \in \mathcal{P}} \sum_{t \in \mathcal{T}} \sum_{\xi \in \Xi} P^{\xi} \cdot\left(v r_{t \xi}^{s p} \cdot \frac{D_{s p} p}{T S^{t}} \cdot U S^{t}\right) \\
& E R=\sum_{s \in \mathcal{S}} \sum_{p \in \mathcal{P}} \sum_{\xi \in \Xi} P^{\xi} \cdot R r \cdot r a_{\xi}^{s p} \\
& E P=\sum_{s \in \mathcal{S}} \sum_{p \in \mathcal{P}} \sum_{\xi \in \Xi} P^{\xi} \cdot E r \cdot r a_{\xi}^{s p}+\sum_{c \in \mathcal{C}} \sum_{p \in \mathcal{P}} \sum_{l \in \mathcal{L}} \sum_{\xi \in \Xi} P^{\xi} \cdot E u_{l} \cdot u q_{\xi}^{c p} \cdot z^{p l} \\
& E T=\sum_{z \in \mathcal{Z}} \sum_{b \in \mathcal{B}} \sum_{t \in \mathcal{T}} \sum_{\xi \in \Xi} P^{\xi} \cdot D_{z b} \cdot \varepsilon_{t} \cdot v a_{t \xi}^{z b}+\sum_{z \in \mathcal{Z}} \sum_{c \in \mathcal{C}} \sum_{t \in \mathcal{T}} \sum_{\xi \in \Xi} P^{\xi} \cdot D_{z c} \cdot \varepsilon_{t} \cdot\left(v p_{t \xi}^{z c}+v h_{t \xi}^{c z}\right) \\
& +\sum_{c \in C} \sum_{p \in \mathcal{P}} \sum_{t \in \mathcal{T}} \sum_{\xi \in \Xi} P^{\xi} \cdot D_{c p} \cdot \varepsilon_{t} \cdot\left(v q_{t \xi}^{c p}+v g_{t \xi}^{p c}\right) \\
& +\sum_{s \in \mathcal{S}} \sum_{p \in \mathcal{P}} \sum_{t \in \mathcal{T}} \sum_{\xi \in \Xi} P^{\xi} \cdot D_{s p} \cdot \varepsilon_{t} \cdot v r_{t \xi}^{s p}
\end{aligned}
$$

subject to:

$$
\begin{gathered}
\sum_{b \in \mathcal{B}} u a_{\xi}^{z b} \leq R^{z \xi} \cdot(1-R u) \forall z \in \mathcal{Z}, \xi \in \Xi, \\
\sum_{z \in \mathcal{Z}} u a_{\xi}^{z b} \leq \sum_{l \in \mathcal{L}} C u^{b l} \cdot x^{b l} \forall b \in \mathcal{B}, \xi \in \Xi, \\
\sum_{z \in \mathcal{Z}} \sum_{b \in \mathcal{B}} u a_{\xi}^{z b}=R^{z \xi} \cdot(1-R u) \forall \xi \in \Xi, \\
\sum_{c \in \mathcal{C}} u p_{\xi}^{z c} \leq R^{z \xi} \cdot R u \forall z \in \mathcal{Z}, \xi \in \Xi, \\
\sum_{z \in \mathcal{Z}} u p_{\xi}^{z c} \leq \sum_{l \in \mathcal{L}} D u^{c l} \cdot y^{c l} \forall c \in \mathcal{C}, \xi \in \Xi, \\
\sum_{p \in \mathcal{P}} u q_{\xi}^{c p} \leq \sum_{z \in \mathcal{Z}} u p_{\xi}^{z c} \forall c \in C, \xi \in \Xi, \\
\sum_{c \in \mathcal{C}} u q_{\xi}^{c p} \leq \sum_{l \in \mathcal{L}} P u^{p l} \cdot z^{p l} \forall p \in \mathcal{P}, \xi \in \Xi, \\
\sum_{p \in \mathcal{P}} \sum_{c \in C} u q_{\xi}^{c p}=\sum_{z \in \mathcal{Z}} \sum_{c \in C} u p_{\xi}^{z c} \forall \xi \in \Xi, \\
\sum_{p \in \mathcal{P}} r a_{\xi}^{s p} \leq Q r^{s} \forall s \in \mathcal{S}, \xi \in \Xi, \\
\sum_{s \in \mathcal{S}} r a_{\xi}^{s p} \leq \sum_{l \in \mathcal{L}} H r^{p l} \cdot z^{p l} \forall p \in \mathcal{P}, \xi \in \Xi, \\
\sum_{c \in C} n p_{\xi}^{p c} \leq \sum_{s \in \mathcal{S}} r a_{\xi}^{s p}+\sum_{c \in C} u q_{\xi}^{c p} \forall p \in \mathcal{P}, \xi \in \Xi, \\
\sum_{p \in \mathcal{P}} n p_{\xi}^{p c} \leq \sum_{l \in \mathcal{L}} H n^{c l} \forall c \in \mathcal{C}, \xi \in \Xi,
\end{gathered}
$$




$$
\begin{gathered}
\sum_{z \in \mathcal{Z}} n q_{\xi}^{c z} \leq \sum_{p \in \mathcal{P}} n p_{\xi}^{p c} \forall c \in \mathcal{C}, \xi \in \Xi, \\
\sum_{c \in C} n q_{\xi}^{c z} \geq D^{z \xi} \forall z \in \mathcal{Z}, \xi \in \Xi, \\
\varphi a_{t \xi}^{z b} \cdot W u \leq W^{t}, \varphi a_{t \xi}^{z b} \cdot V u \leq V^{t} \forall z \in \mathcal{Z}, b \in \mathcal{B}, t \in \mathcal{T}, \xi \in \Xi, \\
\sum_{t \in \mathcal{T}} \varphi a_{t \xi}^{z b} \cdot v a_{t \xi}^{z b} \geq u a_{\xi}^{z b} \forall z \in \mathcal{Z}, b \in \mathcal{B}, \xi \in \Xi,
\end{gathered}
$$

$\varphi p_{t \xi}^{z \mathcal{c}} \cdot W u \leq W^{t}, \varphi p_{t \xi}^{z \mathcal{c}} \cdot V u \leq V^{t} \forall z \in \mathcal{Z}, c \in \mathcal{C}, t \in \mathcal{T}, \xi \in \Xi$,

$$
\sum_{t \in \mathcal{T}} \varphi p_{t \xi}^{z \mathcal{C}} \cdot v p_{t \xi}^{z c} \geq u p_{\xi}^{z \mathcal{C}} \forall z \in \mathcal{Z}, c \in \mathcal{C}, \xi \in \Xi
$$

$\varphi q_{t \xi}^{c p} \cdot W u \leq W^{t}, \varphi q_{t \xi}^{c p} \cdot V u \leq V^{t} \forall c \in C, p \in \mathcal{P}, t \in \mathcal{T}, \xi \in \Xi$,

$$
\begin{gathered}
\sum_{t \in \mathcal{T}} \varphi q_{t \xi}^{c p} \cdot v q_{t \xi}^{c p} \geq u q_{\xi}^{c p} \forall c \in \mathcal{C}, p \in \mathcal{P}, \xi \in \Xi, \\
\varphi r_{t \xi}^{s p} \cdot W r \leq W^{t}, \varphi r_{t \xi}^{s p} \cdot V r \leq V^{t} \forall s \in \mathcal{S}, p \in \mathcal{P}, t \in \mathcal{T}, \xi \in \Xi, \\
\sum_{t \in \mathcal{T}} \varphi r_{t \xi}^{s p} \cdot v r_{t \xi}^{s p} \geq r a_{\xi}^{s p} \forall s \in \mathcal{S}, p \in \mathcal{P}, \xi \in \Xi, \\
\varphi g_{t \xi}^{p c} \cdot W n \leq W^{t}, \varphi g_{t \xi}^{p c} \cdot V n \leq V^{t} \forall p \in \mathcal{P}, c \in \mathcal{C}, t \in \mathcal{T}, \xi \in \Xi, \\
\sum_{t \in \mathcal{T}} \varphi g_{t \xi}^{p c} \cdot v g_{t \xi}^{p c} \geq n p_{\xi}^{p c} \forall p \in \mathcal{P}, c \in \mathcal{C}, \xi \in \Xi,
\end{gathered}
$$

$\varphi h_{t \xi}^{c z} \cdot W n \leq W^{t}, \varphi h_{t \xi}^{c z} \cdot V n \leq V^{t} \forall c \in C, z \in \mathcal{Z}, t \in \mathcal{T}, \xi \in \Xi$,

$$
\begin{gathered}
\sum_{t \in \mathcal{T}} \varphi h_{t \xi}^{c z} \cdot v h_{t \xi}^{c z} \geq n q_{\xi}^{c z} \forall c \in C, z \in \mathcal{Z}, \xi \in \Xi, \\
\sum_{l \in \mathcal{L}} x^{b l}=1 \forall b \in \mathcal{B}, \\
\sum_{l \in \mathcal{L}} y^{c l}=1 \forall c \in \mathcal{C}, \\
\sum_{l \in \mathcal{L}} z^{p l}=1 \forall p \in \mathcal{P}, \\
\sum_{b \in \mathcal{B}} \sum_{l \in \mathcal{L}} \frac{I B^{b l} \cdot x^{b l}}{I B^{b l}} \leq D C, \\
\sum_{c \in \mathcal{C}} \sum_{l \in \mathcal{L}} \frac{I C^{c l} \cdot y^{c l}}{I C^{c l}} \leq H D, \\
\sum_{p \in \mathcal{P}} \sum_{l \in \mathcal{L}} \frac{I P^{p l} \cdot z^{p l}}{I P^{p l}} \leq H P, \\
x^{b l}, y^{c l}, z^{p l} \in\{0,1\} \forall l \in \mathcal{L}, b \in \mathcal{B}, c \in C, p \in \mathcal{P},
\end{gathered}
$$

$u a_{\xi}^{z b}, u p_{\xi}^{z c}, u q_{\xi}^{c p}, r a_{\xi}^{s p}, n p_{\xi}^{p c}, n q_{\xi}^{c z}, \varphi a_{t \xi^{\prime}}^{z b} \varphi p_{t \xi^{\prime}}^{z c} \varphi q_{t \xi^{\prime}}^{c p}, \varphi r_{t \xi^{\prime}}^{s p} \varphi g_{t \xi^{\prime}}^{p c} \varphi h_{t \xi^{\prime}}^{c z}, v a_{t \xi^{\prime}}^{z b}, v p_{t \xi^{\prime}}^{z c}, v q_{t \xi^{\prime}}^{c p}, v r_{t \xi^{\prime}}^{s p}$, $v g_{t^{\prime},}^{p c} v h_{t \xi}^{c z} \geq 0$ \& integer variables $\forall z \in \mathcal{Z}, b \in \mathcal{B}, c \in \mathcal{C}, p \in \mathcal{P}, s \in \mathcal{S}, t \in \mathcal{T}, \xi \in \Xi$, 
where constraint (3) restricts the outgoing used products for disposal not to exceed the supplied quantity at each customer zone. Constraint (4) guarantees that the incoming used products do not exceed the capacity at each disposal center. Constraint (5) guarantees that the total used products for disposal need to be delivered to disposal centers. Constraint (6) restricts the outgoing used products for recovery not to exceed the supplied quantity at each customer zone. Constraint (7) guarantees the incoming used products do not exceed the capacity at each HDC center. Constraint (8) restricts the outgoing used products so they do not exceed the supplied quantity at each HDC center. Constraint (9) guarantees the incoming used products do not exceed the capacity at each HPR plant. Constraint (10) ensures the transportation balance of used products between HDC centers and HPR plants. Constraint (11) restricts the total outgoing raw materials so they do not exceed the available quantity at each supplier. Constraint (12) guarantees the incoming used products do not exceed the capacity at each potential HPR plant. Constraint (13) restricts the outgoing new products so they do not exceed the supplied quantity of raw materials and used products at each potential HPR plant. Constraint (14) guarantees the incoming new products do not exceed the capacity at each potential HDC center. Constraint (15) restricts the outgoing new products so they do not surpass the supplied quantity of new products at each potential HDC center. Constraint (16) guarantees that the demand for new products at customer zones should be met. Constraints (17) and (18) guarantee that assigned vehicles are able to deliver the used products from customer zones to disposal centers. Constraints (19) and (20) guarantee that assigned vehicles are able to deliver used products from customer zones to HDC centers. Constraints (21) and (22) guarantee that assigned vehicles are able to deliver used products from HDC centers to HPR plants. Constraints (23) and (24) guarantee that assigned vehicles are able to deliver raw materials from suppliers to potential HPR plants. Constraints (25) and (26) guarantee that assigned vehicles are able to deliver new products from potential HPR plants to potential HDC centers. Constraints (27) and (28) guarantee that assigned vehicles are able to deliver new products from potential HDC centers to customer zones. Constraints (29)-(31) provide a restriction that only one investment level can be selected. Constraints (32)-(34) restrict the numbers of disposal centers, HDC centers, and HPR plants, respectively. Constraints (35) and (36) define the decision variables.

\subsection{Linearization Method}

In stochastic optimization, two approaches are usually applied to tackle the uncertainty issues, where the uncertainty can be described as the continuously distributed evens or a set of discrete scenarios. In this study, a scenario-based approach has been applied to represent the uncertain demand for new products and return quantity of used products. The proposed model is a stochastic integer nonlinear programming model due to the constraints (18), (20), (22), (24), (26), (28), and (32)-(34). To linearize the model, three auxiliary integer parameters $\left(\beta u^{t *}, \beta n^{t *}\right.$, and $\left.\beta r^{t *}\right)$ are introduced into this model, which are the maximal integer numbers of stored used products, new products, and raw materials for each type of vehicles. These three parameters can be obtained according to the following formulas:

$$
\begin{aligned}
& \beta u^{t *}=\min \frac{W^{t}}{W u}, \frac{V^{t}}{V u} \forall t \in \mathcal{T}, \\
& \beta n^{t *}=\min \frac{W^{t}}{W n}, \frac{V^{t}}{V n} \forall t \in \mathcal{T}, \\
& \beta r^{t *}=\min \frac{W^{t}}{W r}, \frac{V^{t}}{V r} \forall t \in \mathcal{T},
\end{aligned}
$$

To linearize the constraints (32)-(34), three auxiliary binary variables are introduced as follows:

$$
I b_{b l}= \begin{cases}0 & \text { No investment is conducted at disposal center } b, \\ 1 & \text { Otherwise; }\end{cases}
$$




$$
\begin{aligned}
& I c_{c l}= \begin{cases}0 & \text { No investment is conducted at distribution center } c, \\
1 & \text { Otherwise; }\end{cases} \\
& I p_{p l}= \begin{cases}0 & \text { No investment is conducted at production plant } p, \\
1 & \text { Otherwise; }\end{cases}
\end{aligned}
$$

Based on the previously introduced parameters and variables, the original model $\mathbb{P}$ can be reformulated as the following model $\mathbb{Q}$ :

$$
\begin{aligned}
& \mathbb{Q}: \\
& \operatorname{Max} \Psi_{1} \\
& \operatorname{Min} \Psi_{2} \\
& \text { subject to: } \\
& \text { Constraints (3)-(16) and (29)-(31). } \\
& \sum_{t \in \mathcal{T}} v a_{t \xi}^{z b} \cdot \beta u^{t *} \geq u a_{\xi}^{z b} \forall z \in \mathcal{Z}, b \in \mathcal{B}, \xi \in \Xi . \\
& \sum_{t \in \mathcal{T}} v p_{t \xi}^{z \mathcal{C}} \cdot \beta u^{t *} \geq u p_{\xi}^{z \mathcal{c}} \forall z \in \mathcal{Z}, c \in \mathcal{C}, \xi \in \Xi . \\
& \sum_{t \in \mathcal{T}} v q_{t \xi}^{c p} \cdot \beta u^{t *} \geq u q_{\xi}^{c p} \forall c \in C, p \in \mathcal{P}, \xi \in \Xi . \\
& \sum_{t \in \mathcal{T}} v r_{t \xi}^{s p} \cdot \beta r^{t *} \geq r a_{\xi}^{s p} \forall s \in \mathcal{S}, p \in \mathcal{P}, \xi \in \Xi . \\
& \sum_{t \in \mathcal{T}} v g_{t \xi}^{p c} \cdot \beta n^{t *} \geq n p_{\xi}^{p c} \forall p \in \mathcal{P}, c \in C, \xi \in \Xi . \\
& \sum_{t \in \mathcal{T}} v h_{t \xi}^{c z} \cdot \beta n^{t *} \geq n q_{\xi}^{c z} \forall c \in \mathcal{C}, z \in \mathcal{Z}, \xi \in \Xi . \\
& \sum_{b \in \mathcal{B}} \sum_{l \in \mathcal{L}} I b_{b l} \cdot x^{b l} \leq D C . \\
& \sum_{c \in C} \sum_{l \in \mathcal{L}} I c_{c l} \cdot y^{c l} \leq H D \text {. } \\
& \sum_{p \in \mathcal{P}} \sum_{l \in \mathcal{L}} I p_{p l} \cdot z^{p l} \leq H P . \\
& u a_{\xi}^{z b}, u p_{\xi}^{z c}, u q_{\xi}^{c p}, r a_{\xi}^{s p}, n p_{\xi}^{p c}, n q_{\xi}^{c z}, v a_{t \xi}^{z b}, v p_{t \xi}^{z c}, v q_{t \xi}^{c p}, v r_{t \xi}^{s p}, v g_{t \xi}^{p c}, v h_{t \xi}^{c z} \geq 0 \text { \& integer } \\
& \text { variables } \forall z \in \mathcal{Z}, b \in \mathcal{B}, c \in C, p \in \mathcal{P}, s \in \mathcal{S}, t \in \mathcal{T}, \xi \in \Xi \text {. }
\end{aligned}
$$

where constraint (40) guarantees that assigned vehicles are able to deliver the used products from customer zones to disposal centers. Constraint (41) guarantees that assigned vehicles are able to deliver the used products from customer zones to HDC centers. Constraint (42) guarantees that assigned vehicles are able to deliver the used products from HDC centers to HPR plants. Constraint (43) guarantees that assigned vehicles are able to deliver the raw materials from suppliers to potential HPR plants. Constraint (44) guarantees that assigned vehicles are able to deliver the new products from potential HPR plants to potential HDC centers. Constraint (45) guarantees that assigned vehicles are able to deliver new products from potential HDC centers to customer zones. Constraints (46)-(48) restrict the numbers of disposal centers, HDC centers, and HPR plants, respectively. Constraint (49) defines the decision variables. 


\subsection{Weighted-Sum Method}

There exists several solution methods that have been proposed for the bi-objective programming model with two conflicting objectives. The conventional bi-objective optimization techniques that are widely used in practice include weighted-sum, $\mathcal{E}$-constraint, weighted metric, and lexicographic goal programming approaches. The weighted-sum method [58-61] is applied in this study due to several reasons. The weighted-sum method provides a structured approach to deal with the problem with various objectives and criteria. Besides, the weighted-sum method provides a means of communication for negotiating the strengths of the criteria and communicates the intermediate and final results. In addition, the weighted-sum method is easy to incorporate weights or relative importance to create an integrated analysis of profit and carbon emissions. Thus, the weighted-sum approach is suitable to be applied in this study. Suppose that $w_{i}$ denotes the relative weight of importance of the criterion (i.e., profit and carbon emissions), such that $\sum_{i} w_{i}=1$. After considering those two criteria simultaneously, the previous bi-objective stochastic integer programming model can be formulated as the following single-objective stochastic integer programming model $\mathbb{R}$.

$$
\begin{aligned}
& \mathbb{R}: \\
& \operatorname{Max} Z\left(w_{1}, w_{2}\right)=w_{1} \cdot \Psi_{1}-w_{2} \cdot \Psi_{2} \\
& \text { subject to: } \\
& \text { Constraints (3)-(16), (29)-(31), and (40)-(49). }
\end{aligned}
$$

where $\mathrm{Z}\left(w_{1}, w_{2}\right)$ is the weighted-sum objective function, and $w_{1}$ and $w_{2}$ are the relative weight values of profit and carbon emissions, respectively.

\section{Numerical Analysis}

\subsection{Numerical Instance}

To demonstrate the validity of the proposed stochastic optimization model and obtain an insight into the behavior of reverse logistics network design, an existing forward logistics network is carried out with different experiments. In the forward logistics direction, there are three suppliers that provide raw materials for three production plants. The new products are produced at production plants and transported to five customer zones to meet the demand via four distribution centers. In the reverse logistics direction, the used products are inspected into two categories according to their quality levels at customer zones. Those used products with lower quality levels are delivered to four potential disposal centers. The used products with higher quality levels are recovered at HPR plants. The maximum numbers of disposal centers, HPR plants, and HDC centers are three, two, and three, respectively. The quantities of available raw materials at three suppliers are 3000, 4000, and 3500, respectively. Two vehicle types with gross weights between $16 t$ and $32 t$, and between $32 t$ and $40 t$ are considered. They have different volume capacities (i.e., 25 and 50), weight capacities (i.e., 16 and 40), travel speeds (i.e., 80 and 70 on the highway), and unit shipping costs (i.e., 12 and 16), respectively. After applying those two vehicles with weight capacities and speeds, the corresponding carbon emission $\left(\mathrm{CO}_{2}\right)$ factors suggested by Hickman, et al. [46] can be obtained, which are $0.796(\mathrm{~kg} / \mathrm{km})$ and $1.066(\mathrm{~kg} / \mathrm{km})$ for small and large vehicles, respectively. Raw material, new product, and used product have different weights (i.e., 0.8, 1.6, and 1.4) and volumes (i.e., 1.0, 1.2, and 1.0). The cost of producing one new product using one raw material is 20 and the price of purchasing one raw material is 15 . The quantity of previous carbon emissions of one raw material is 20 and the quantity of carbon emissions of producing one new product using one raw material is 15 . The price of selling one new product at customer zone is 110. The cost of purchasing one used product at customer zones and the price of selling one used product at disposal centers are the same. In addition, the cost of producing one new product using one used product is 15 . The distance from customer zones to disposal 
centers and distribution centers is randomly generated on the interval [80,200]. The distance from production plants to suppliers and distribution centers is randomly generated on the interval [250, 750]. Four investment levels are considered and the first investment level is 0 , which means no investment. Specifically, the remaining three investment levels at disposal centers are integers randomly generated on the intervals [200, 300], [260,360], and [300,450] with the corresponding capacities generated on the intervals [280, 350], [300, 420], and [420, 480], respectively. At distribution centers, the first investment level is 0 and the capacities of new products are randomly generated on the interval [3500,5500]. The remaining three investment levels at disposal centers are integers randomly generated on the intervals [300, 500], [500, 600], and [600, 850] with the corresponding new-product capacities generated on the intervals [2500,3000], [3000, 3500], and [3500, 4000], as well as the used-product capacities generated on the intervals [400, 800], [800,1200], and [1200, 1600], respectively. At production plants, the first investment level is 0 and the capacities of raw materials are integers randomly generated on the interval $[5500,7000]$. The remaining three investment levels at disposal centers are integers randomly generated on the intervals [1200, 1600], [1600, 2000], and [2000, 2500] with the corresponding raw-material capacities randomly generated on the intervals [2800, 3500], [3500, 4000], and [4000, 4500], as well as the used-product capacities randomly generated on the intervals [100, 1400], [1400, 1800], and [1800, 2500], respectively. In addition, the quantities of carbon emissions of producing one new product using one used product under the last three investment levels are 10, 8, and 5, respectively. Two scenarios are considered in this study with probabilities of 0.6 and 0.4. The quantities of used products at customer zones in both scenarios are integers randomly generated on the intervals [300, 600] and $[200,400]$, respectively. The return rate of used products for recovery is 0.6 . The demand for new products at customer zones in both scenarios are integers randomly generated on the intervals $[1200,2000]$ and $[600,1200]$, respectively. Based on the previously given parameters, the model $\mathbb{R}$ is implemented in the IBM ILOG CPLEX Optimization Studio (Version: 12.6). All the experiments are run on a computer with an Intel(R) Core(TM) i7-7700 CPU@3.6 GHz and 8 GB memory under the Windows 10 Pro system.

\subsection{Experimental Results}

To better understand the behavior of the design of the reverse logistics network, the impact of a set of relative weight values is examined. Different relative weight values are considered and tested as they influence the selections of disposal centers, HDC centers with investment levels, and HPR plants with investment levels. The investment levels of disposal centers, HDC centers, and HPR plants are presented in Table 1 under 11 sets of relative weight values. As shown in Table 1 , as $w_{2}$ increases from 0 to 1.0, more HDC centers and HPR plants with higher investment levels are reconstructed, because the importance of carbon emissions is emphasized and HPR plants with higher investment levels enable to reduce the carbon emissions of the system.

Table 1. Investment levels at disposal centers, HDC centers, and HPR plants.

\begin{tabular}{lccccccccccccc}
\hline \multirow{2}{*}{ No. } & Relative Weight Values $\left(\boldsymbol{w}_{\mathbf{1}}, \boldsymbol{w}_{\mathbf{2}}\right)$ & \multicolumn{4}{c}{$\boldsymbol{P}$} & \multicolumn{4}{c}{$\boldsymbol{C}$} & \multicolumn{6}{c}{$\mathcal{B}$} \\
\cline { 3 - 12 } & & $\mathbf{1}$ & $\mathbf{2}$ & $\mathbf{3}$ & $\mathbf{1}$ & $\mathbf{2}$ & $\mathbf{3}$ & $\mathbf{4}$ & $\mathbf{1}$ & $\mathbf{2}$ & $\mathbf{3}$ & $\mathbf{4}$ \\
\hline 1 & $(0,1.0)$ & $l 4$ & $l 1$ & $l 4$ & $l 4$ & $l 4$ & $l 4$ & $l 1$ & $l 4$ & $l 4$ & $l 4$ & $l 1$ \\
2 & $(0.1,0.9)$ & $l 4$ & $l 1$ & $l 4$ & $l 1$ & $l 2$ & $l 4$ & $l 1$ & $l 2$ & $l 4$ & $l 2$ & $l 1$ \\
3 & $(0.2,0.8)$ & $l 4$ & $l 1$ & $l 1$ & $l 1$ & $l 2$ & $l 4$ & $l 1$ & $l 2$ & $l 4$ & $l 2$ & $l 1$ \\
4 & $(0.3,0.7)$ & $l 4$ & $l 1$ & $l 1$ & $l 1$ & $l 2$ & $l 4$ & $l 2$ & $l 4$ & $l 2$ & $l 1$ & $l 1$ \\
5 & $(0.4,0.6)$ & $l 4$ & $l 1$ & $l 1$ & $l 1$ & $l 2$ & $l 4$ & $l 1$ & $l 2$ & $l 4$ & $l 2$ & $l 1$ \\
6 & $(0.5,0.5)$ & $l 4$ & $l 1$ & $l 1$ & $l 1$ & $l 2$ & $l 4$ & $l 1$ & $l 2$ & $l 3$ & $l 2$ & $l 1$ \\
7 & $(0.6,0.4)$ & $l 4$ & & $l 1$ & $l 1$ & $l 2$ & $l 4$ & $l 1$ & $l 2$ & $l 3$ & $l 2$ & $l 1$ \\
8 & $(0.7,0.3)$ & $l 4$ & $l 1$ & $l 1$ & $l 1$ & $l 1$ & $l 4$ & $l 1$ & $l 2$ & $l 2$ & $l 2$ & $l 1$ \\
9 & $(0.8,0.2)$ & $l 1$ & $l 1$ & $l 1$ & $l 1$ & $l 1$ & $l 1$ & $l 1$ & $l 2$ & $l 2$ & $l 2$ & $l 1$ \\
10 & $(0.9,0.1)$ & $l 1$ & $l 1$ & $l 1$ & $l 1$ & $l 1$ & $l 1$ & $l 1$ & $l 2$ & $l 2$ & $l 2$ & $l 1$ \\
11 & $(1.0,0)$ & $l 1$ & $l 1$ & $l 1$ & $l 1$ & $l 1$ & $l 1$ & $l 1$ & $l 2$ & $l 2$ & $l 2$ & $l 1$ \\
\hline
\end{tabular}


With the increase of $w_{2}$, the total number of assigned vehicles also changes. Figure 2 represents the total number of small and large vehicles in two scenarios with respect to the change of $w_{2}$. Obviously, more large vehicles are used in both scenarios because the large vehicle can provide a low-carbon emission delivery. Besides, as shown in Figure 2b, there is a gradual increase in the number of large vehicles in both scenarios, because $w_{2}$ changes the item flows in the reverse logistics network.

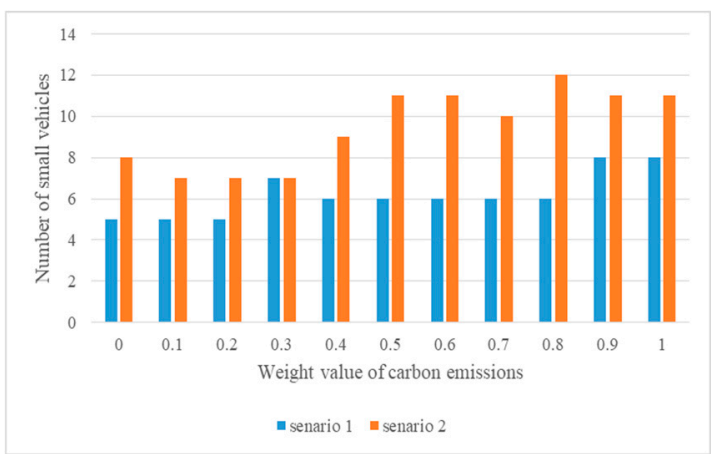

(a)

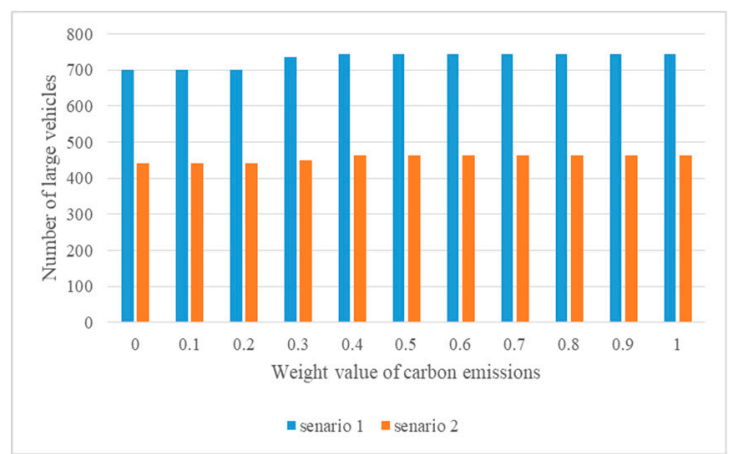

(b)

Figure 2. Number of assigned vehicles given different relative weight values of $w_{2}$.

Besides, the item flows are also affected by the relative weight value $w_{2}$. Given different relative weight values, the total flow of raw-materials from suppliers to production and HPR plants is presented in Figure 3 and the total flow of used products from HDC centers to HPR plants is presented in Figure 4. As shown in Figure 3, the increase of $w_{2}$ from 0 to 1 decreases the total flow of raw materials from suppliers to production and HPR plants. Conversely, the total flow of used products is growing with $w_{2}$. Both Figures 3 and 4 demonstrate that recovering the used products is an efficient way to help HPR plants reduce the carbon emissions.

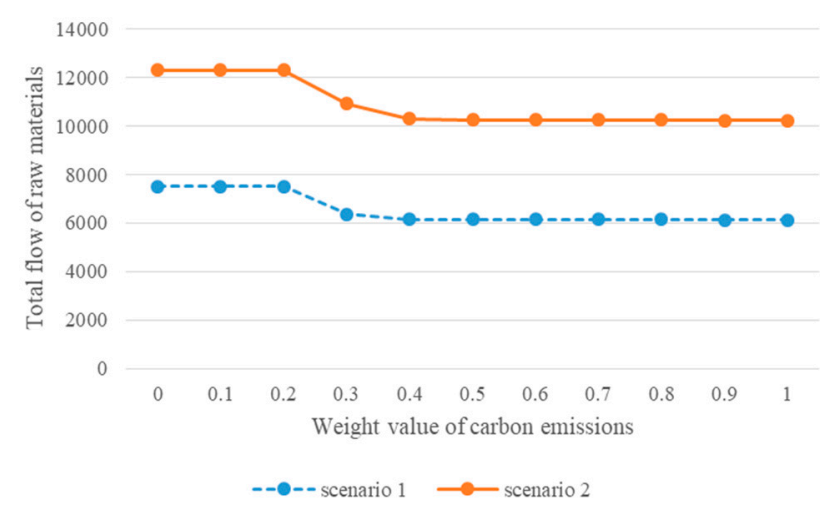

Figure 3. Total flow of raw materials from suppliers to production and HPR plants.

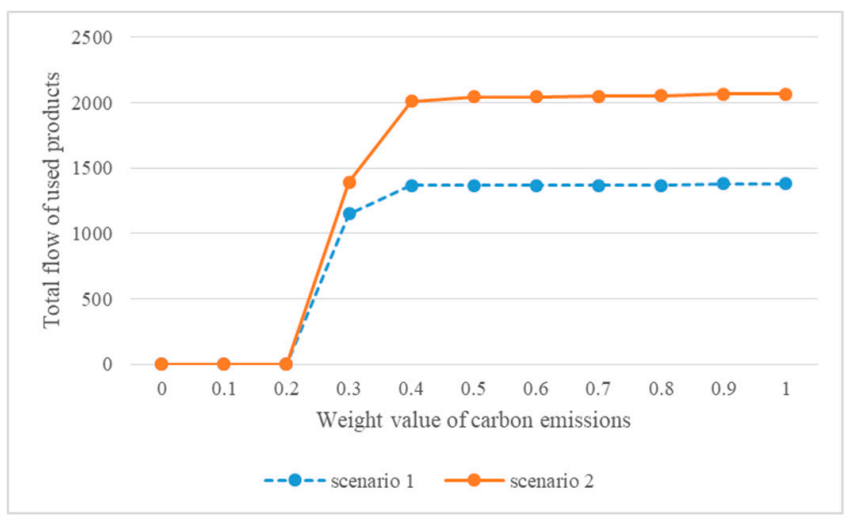

Figure 4. Total flow of used products from HDC centers to HPR plants. 


\subsection{Sensitivity Analysis}

To illustrate the reliability of the multi-level investments at the facilities for the design of the reverse logistics network, different investment policies are examined on the performances of reverse logistics network design. In this study, there are four investment policies that are (i) multi-level investments (i.e., hybrid investments); (ii) investment level 2; (iii) investment level 3; and (iv) investment level 4. The quantity of investment level 3 is higher than investment level 2 and less than investment level 4. Those four investment policies are tested independently and their results are compared as $w_{2}$ goes from 0 to 0.5 . The weighted-sum value of the expected total profit and carbon emissions is presented in Figure 5, where the increase of $w_{2}$ decreases the weighted-sum value of the expected total profit and carbon emissions.

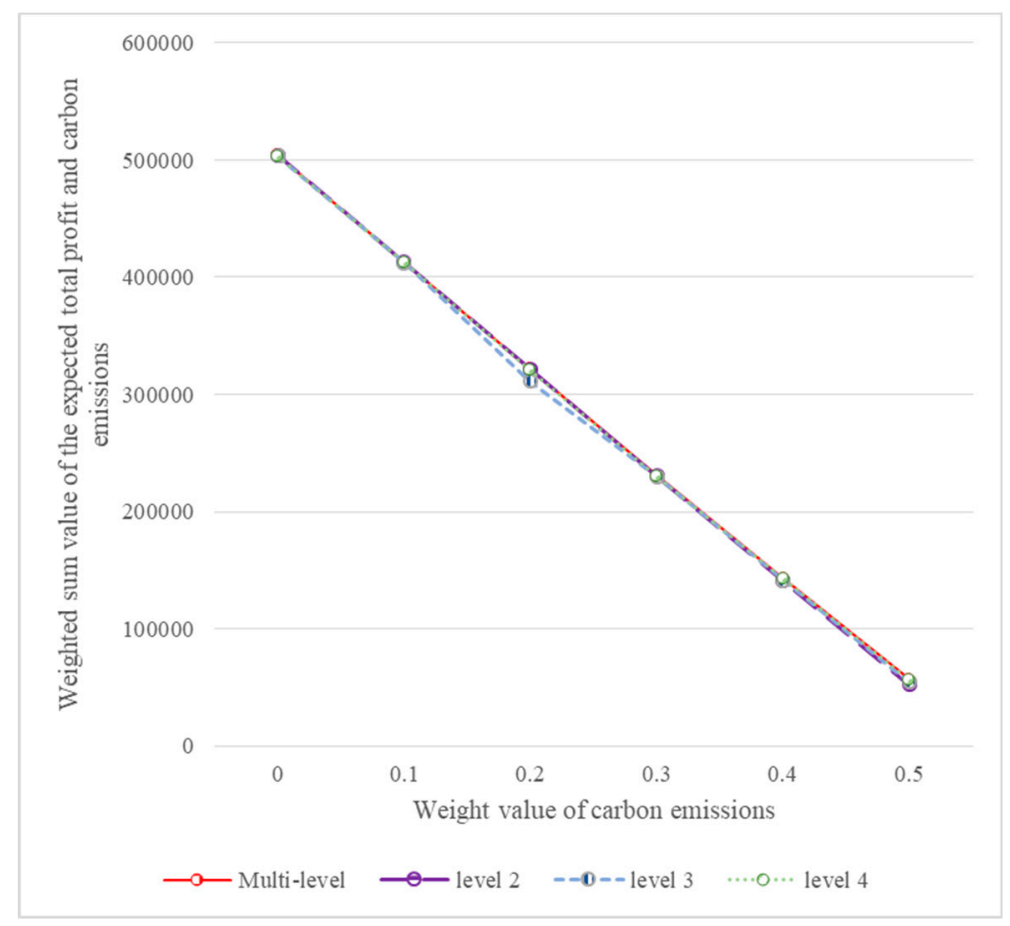

Figure 5. Weighted-sum value of the expected total profit and carbon emissions under different investment policies.

To better show the performances of those four investment policies, the following formula (51) is applied and the results are presented in Figure 6 , where $\Delta \mathrm{Z}\left(w_{1}, w_{2}\right)$ is the relative weighted-sum value of the expected total profit and carbon emissions given $w_{1}$ and $w_{2}$ values. In Figure 6, the relative weighted-sum value of the expected total profit and carbon emissions is presented under each investment policy. Figure 6 also illustrates the great advantage of the first investment policy (multi-level investments) as the maximum weighted-sum value is always obtained as $w_{2}$ goes from 0 to 0.5 . In addition, when $w_{2}$ is greater than 0.2 , a higher investment level can better balance the economic and environmental benefits. Specifically, the fourth investment policy (investment level 4) shows a better performance than investment policies 2 and 3 .

$$
\begin{aligned}
\Delta \mathrm{Z}\left(w_{1}, w_{2}\right)=\mathrm{Z}\left(w_{1}, w_{2}\right) & \\
\quad & -\min \{\mathrm{Z}(1,0), \mathrm{Z}(0.9,0.1), \mathrm{Z}(0.8,0.2), \mathrm{Z}(0.7,0.3), \mathrm{Z}(0.6,0.4), \mathrm{Z}(0.5,0.5)\}
\end{aligned}
$$




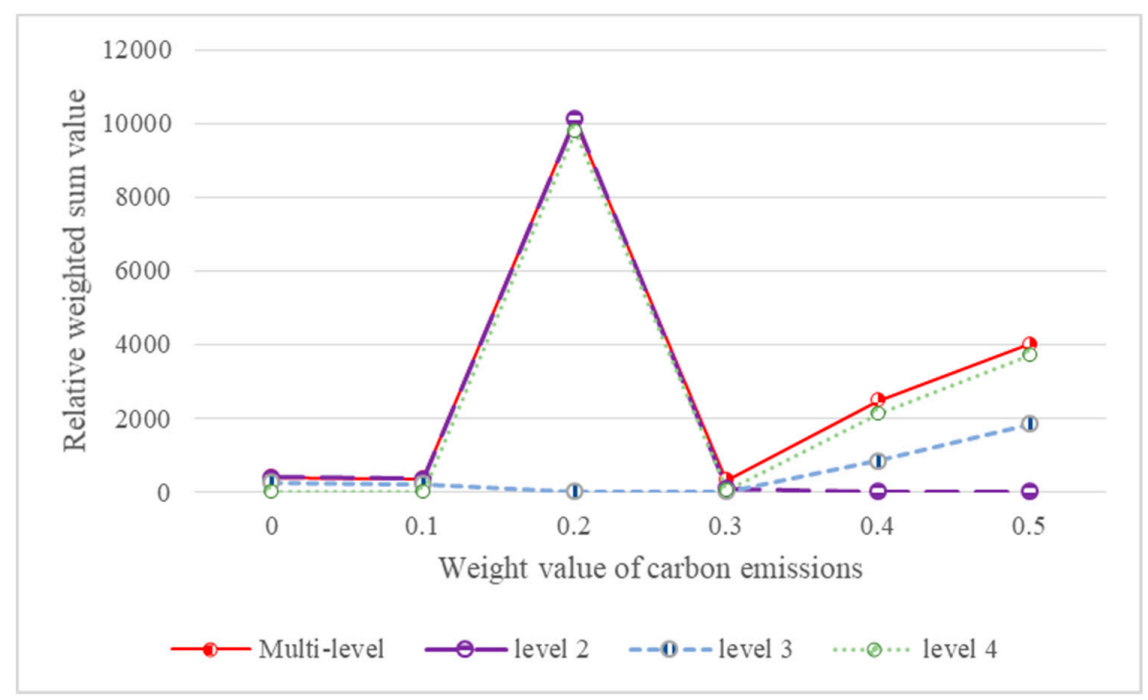

Figure 6. Relative weighted-sum value under different investment policies.

The weighted-sum value $Z$ of the expected total profit and carbon emissions is also affected by the return quantity of used products. To better understand the influence of the return rate $R u$ of used products and relative weight value $w_{2}$, different return rates of used products for recovery and different relative weight values are tested and the corresponding weighted-sum values are presented in Figure 7. It is obvious that the weighted-sum value is also sensitive to the return rate $R u$. Given a specific relative weight value $w_{2}$, the weighted-sum value of the expected total profit and carbon emissions is increasing as the return rate $R u$ goes from 0.4 to 0.8 .

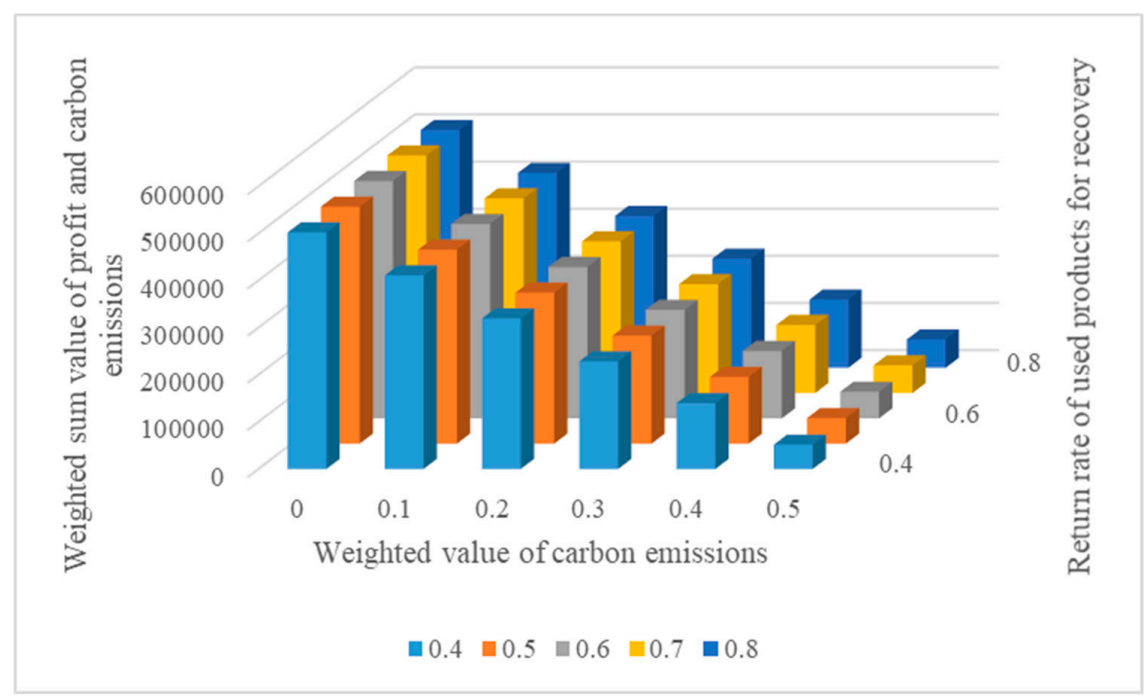

Figure 7. Influence of $R u$ and $w_{2}$ on the performance of the weighted-sum value.

This is because the return rate of used products is directly influencing the item flows, the selection of investment levels at facilities, and the number of used vehicles. Given different return rates of used products for recovery and relative weight values of carbon emissions, the corresponding results are shown in Table 2 . We can see that the increasing $w_{2}$ encourages more used products which are recovered at HPR plants when $w_{2} \geq 0.3$ and $R u \geq 0.5$. From the previous discussion and analysis, the selection of return rate $R u$ and the relative weight value $w_{2}$ can extremely improve the environmental performance of the reverse logistics system. 
Table 2. Investment levels at facilities and assignment vehicles under different $w_{2}$ and $R u$ values.

\begin{tabular}{|c|c|c|c|c|c|c|c|c|}
\hline \multirow{2}{*}{$w_{2}$} & \multirow{2}{*}{$R u$} & \multirow{2}{*}{$z^{p l}$} & \multirow{2}{*}{$y^{c l}$} & \multirow{2}{*}{$x^{b l}$} & \multicolumn{2}{|c|}{ Small Vehicle } & \multicolumn{2}{|c|}{ Large Vehicle } \\
\hline & & & & & $\xi 1$ & $\xi 2$ & $\xi 1$ & $\xi 2$ \\
\hline \multirow{4}{*}{0} & 0.4 & $(l 1, l 1, l 1)$ & $(14,14,14,14)$ & $(14,14,14,14)$ & 6 & 9 & 712 & 447 \\
\hline & 0.5 & $(l 1, l 1, l 1)$ & $(l 1, l 1, l 1, l 1)$ & $(14,14,11,14)$ & 7 & 5 & 705 & 446 \\
\hline & 0.7 & $(l 1, l 1, l 1)$ & $(l 1, l 1, l 1, l 1)$ & $(l 4, l 4, l 1, l 1)$ & 8 & 5 & 691 & 440 \\
\hline & 0.8 & $(l 1, l 1, l 1)$ & $(l 1, l 1, l 1, l 1)$ & $(l 4, l 4, l 1, l 1)$ & 6 & 8 & 685 & 435 \\
\hline \multirow{4}{*}{0.1} & 0.4 & $(l 1, l 1, l 1)$ & $(l 1, l 1, l 1, l 1)$ & $(14,14,14,14)$ & 6 & 9 & 712 & 447 \\
\hline & 0.5 & $(l 1, l 1, l 1)$ & $(l 1, l 1, l 1, l 1)$ & $(14,14,11,14)$ & 7 & 5 & 705 & 446 \\
\hline & 0.7 & $(l 1, l 1, l 1)$ & $(l 1, l 1, l 1, l 1)$ & $(14, l 4, l 1, l 1)$ & 8 & 5 & 691 & 440 \\
\hline & 0.8 & $(l 1, l 1, l 1)$ & $(l 1, l 1, l 1, l 1)$ & $(l 4, l 4, l 1, l 1)$ & 6 & 8 & 685 & 435 \\
\hline \multirow{4}{*}{0.2} & 0.4 & $(l 1, l 1, l 1)$ & $(l 1, l 1, l 1, l 1)$ & $(14,14,14,14)$ & 6 & 9 & 712 & 447 \\
\hline & 0.5 & $(l 1, l 1, l 1)$ & $(l 1, l 1, l 1, l 1)$ & $(14,14, l 1,14)$ & 7 & 5 & 705 & 446 \\
\hline & 0.7 & $(l 1, l 1, l 1)$ & $(l 1, l 1, l 1, l 1)$ & $(l 4, l 4, l 1, l 1)$ & 8 & 5 & 691 & 440 \\
\hline & 0.8 & $(l 1, l 1, l 1)$ & $(l 1, l 1, l 1, l 1)$ & $(l 4, l 4, l 1, l 1)$ & 6 & 8 & 685 & 435 \\
\hline \multirow{4}{*}{0.3} & 0.4 & $(l 1, l 1, l 1)$ & $(l 1, l 1, l 1, l 1)$ & $(14,14,14,14)$ & 6 & 9 & 712 & 447 \\
\hline & 0.5 & $(l 1, l 1, l 1)$ & $(l 1, l 1, l 1, l 1)$ & $(14,14, l 1,14)$ & 7 & 5 & 705 & 446 \\
\hline & 0.7 & $(l 4, l 1, l 1)$ & $(l 1, l 1, l 4, l 1)$ & $(l 4, l 4, l 1, l 1)$ & 8 & 4 & 728 & 449 \\
\hline & 0.8 & $(l 4, l 1, l 1)$ & $(l 1, l 1, l 4, l 1)$ & $(l 4, l 4, l 1, l 1)$ & 8 & 7 & 721 & 444 \\
\hline \multirow{4}{*}{0.4} & 0.4 & $(l 4, l 1, l 1)$ & $(l 1, l 1, l 4, l 1)$ & $(14,14,14,14)$ & 9 & 12 & 740 & 460 \\
\hline & 0.5 & $(l 4, l 1, l 1)$ & $(l 1, l 1, l 4, l 1)$ & $(14,14,14, l 1)$ & 9 & 5 & 742 & 465 \\
\hline & 0.7 & $(l 4, l 1, l 1)$ & $(l 1, l 4, l 4, l 1)$ & $(14, l 4, l 1, l 1)$ & 9 & 4 & 742 & 467 \\
\hline & 0.8 & $(l 4, l 1, l 1)$ & $(l 1, l 4, l 4, l 1)$ & $(l 4, l 4, l 1, l 1)$ & 9 & 10 & 741 & 463 \\
\hline \multirow{4}{*}{0.5} & 0.4 & $(l 4, l 1, l 1)$ & $(l 1, l 1, l 4, l 1)$ & $(14,14,14,14)$ & 8 & 13 & 741 & 461 \\
\hline & 0.5 & $(l 4, l 1, l 1)$ & $(l 1, l 4, l 4, l 1)$ & $(14,14,14, l 1)$ & 11 & 5 & 741 & 465 \\
\hline & 0.7 & $(14, l 1, l 1)$ & $(l 1, l 4, l 4, l 1)$ & $(l 4, l 4, l 1, l 1)$ & 9 & 4 & 742 & 467 \\
\hline & 0.8 & $(l 4, l 1, l 1)$ & $(l 1, l 4, l 4, l 1)$ & $(l 4, l 4, l 1, l 1)$ & 9 & 8 & 741 & 467 \\
\hline
\end{tabular}

\section{Conclusions}

In this paper, we proposed a bi-objective stochastic integer programming model for a novel reverse logistics network design problem based on the existing forward logistics network with the objectives of both economic and environmental benefits. The model aims to support production, recovery, and disposal activities by coping with the uncertain elements of demand for new products and return quantity of used products at customer zones. This novel reverse logistics network design problem is resolved by introducing several auxiliary parameters and variables to linearize the constraints in the proposed stochastic optimization model. To illustrate the validity of the proposed stochastic optimization model, a numerical analysis is conducted and the corresponding results including the facility locations, investment level choices, item flows, and vehicle assignments are presented. Some deep managerial implications are drawn from the previous sensitivity analysis of several key parameters. These managerial implications are obtained in a stochastic environment, which improves the reliability and robustness of the decision-making under market fluctuation.

In the end, we can explore the problem of interests from the following aspects in future studies. (1) This study provides a stochastic programming model for a novel reverse logistics network design problem. It is interesting to extend this model to a robust optimization model. (2) This study is developed based on steady demand from the market. However, when the market demand grows sharply, facility reconstruction may not able to provide enough capacity to produce more new products to meet the demand from the market. So, it is interesting to consider the fluctuation demand on the reverse logistics network design. (3) Another interesting research direction is to consider various risks (i.e., facility disruption and insufficient supply) for a reliable reverse logistics network design. (4) Applying a heuristic solution method is critical due to the increase of complexity time by increasing the size of the problem and the number of scenarios. 
Author Contributions: X.G. conducted the whole contribution to this research. He proposed the mathematical model and the solution method and analyzed the results.

Funding: This research was funded in part by the National Research Foundation of Korea (NRF) grant number (NRF-2017R1A2B4004169) and the China-Korea cooperation program managed by the National Natural Science Foundation of China and the NRF grant number (NRF-2018K2A9A2A06019662).

Acknowledgments: A part of this article is based on the author's unpublished thesis in progress. The author also wishes to thank Professor Chanseok Park at Pusan National University for his encouragement and financial support.

Conflicts of Interest: The authors declare no conflict of interest.

\section{References}

1. Professionals, Council of Supply Chain Management Professionals. Supply Chain Management Terms and Glossary; Council of Supply Chain Management Professionals (CSCMP): Lombard, IL, USA, 2013.

2. Altiparmak, F.; Gen, M.; Lin, L.; Karaoglan, I. A steady-state genetic algorithm for multi-product supply chain network design. Comput. Ind. Eng. 2009, 56, 521-537. [CrossRef]

3. Arvan, M.; Tavakkoli-Moghaddam, R.; Abdollahi, M. Designing a bi-objective and multi-product supply chain network for the supply of blood. Uncertain Supply Chain Manag. 2015, 3, 57-68. [CrossRef]

4. Bahrampour, P.; Safari, M.; Taraghdari, M.B. Modeling Multi-Product Multi-Stage Supply Chain Network Design. Procedia Econ. Financ. 2016, 36, 70-80. [CrossRef]

5. Sampat, A.M.; Martin, E.; Martin, M.; Zavala, V.M. Optimization formulations for multi-product supply chain networks. Comput. Chem. Eng. 2017, 104, 296-310. [CrossRef]

6. Cao, C.; Li, C.; Yang, Q.; Zhang, F. Multi-Objective Optimization Model of Emergency Organization Allocation for Sustainable Disaster Supply Chain. Sustainability 2017, 9, 2103. [CrossRef]

7. Niknejad, A.; Petrovic, D. Optimisation of integrated reverse logistics networks with different product recovery routes. Eur. J. Oper. Res. 2014, 238, 143-154. [CrossRef]

8. Zarbakhshnia, N.; Soleimani, H.; Goh, M.; Razavi, S.S. A novel multi-objective model for green forward and reverse logistics network design. J. Clean. Prod. 2019, 208, 1304-1316. [CrossRef]

9. Rogers, S.D.; Tibben-Lembke, R. An examination of reverse logistics practices. J. Bus. Logist. 2001, 22, 129-148. [CrossRef]

10. Barrera, M.M.M.; Cruz-Mejia, O. Reverse logistics of recovery and recycling of non-returnable beverage containers in the brewery industry: A "profitable visit" algorithm. Int. J. Phys. Distr. Logist. Manag. 2014, 44, 577-596. [CrossRef]

11. Guarnieri, P.; Silva, L.C.; Levino, N.A. Analysis of electronic waste reverse logistics decisions using Strategic Options Development Analysis methodology: A Brazilian case. J. Clean. Prod. 2016, 133, 1105-1117. [CrossRef]

12. Govindan, K.; Soleimani, H. A review of reverse logistics and closed-loop supply chains: A Journal of Cleaner Production focus. J. Clean. Prod. 2017, 142, 371-384. [CrossRef]

13. Schultmann, F.; Zumkeller, M.; Rentz, O. Modeling reverse logistics tasks within closed-loop supply chains: An example from the automotive industry. Eur. J. Operat. Res. 2006, 171, 1033-1050. [CrossRef]

14. Lee, H.D.; Dong, M. A heuristic approach to logistics network design for end-of-lease computer products recovery. Transp. Res. Part E Logist. Transp. Rev. 2008, 44, 455-474. [CrossRef]

15. Verstrepen, S.; Cruijssen, F.; De Brito, M.; Dullaert, W. An exploratory analysis of reverse logistics in Flanders. Eur. J. Trans. Infrastruct. Res. 2007, 7, 301-316.

16. Keyvanshokooh, E.; Fattahi, M.; Seyed-Hosseini, S.; Tavakkoli-Moghaddam, R. A dynamic pricing approach for returned products in integrated forward/reverse logistics network design. Appl. Math. Modell. 2013, 37, 10182-10202. [CrossRef]

17. Üster, H.; Easwaran, G.; Akçali, E.; Çetinkaya, S. Benders decomposition with alternative multiple cuts for a multi-product closed-loop supply chain network design model. Naval Res. Logist. 2007, 54, 890-907. [CrossRef]

18. Cardoso, R.S.; Barbosa-Póvoa, A.P.F.; Relvas, S. Design and planning of supply chains with integration of reverse logistics activities under demand uncertainty. Eur. J. Op. Res. 2013, 226, 436-451. [CrossRef]

19. Lee, H.D.; Dong, M. Dynamic network design for reverse logistics operations under uncertainty. Transp. Res. Part E Logist. Transp. Rev. 2009, 45, 61-71. [CrossRef] 
20. Wang, F.; Lai, X.; Shi, N. A multi-objective optimization for green supply chain network design. Decis. Supp. Syst. 2011, 51, 262-269. [CrossRef]

21. Yu, H.; Solvang, W.D. A general reverse logistics network design model for product reuse and recycling with environmental considerations. Int. J. Adv. Manuf. Technol. 2016, 87, 2693-2711. [CrossRef]

22. Qiang, Q.; Ke, K.; Anderson, T.; Dong, J. The closed-loop supply chain network with competition, distribution channel investment, and uncertainties. Omega 2013, 41, 186-194. [CrossRef]

23. Agrawal, S.; Singh, R.K.; Murtaza, Q. A literature review and perspectives in reverse logistics. Resour. Conserv. Recycl. 2015, 97, 76-92. [CrossRef]

24. Prajapati, H.; Kant, R.; Shankar, R. Bequeath life to death: State-of-art review on reverse logistics. J. Clean. Prod. 2019, 211, 503-520. [CrossRef]

25. Pokharel, S.; Mutha, A. Perspectives in reverse logistics: A review. Resour. Conserv. Recycl. 2009, 53, $175-182$. [CrossRef]

26. Min, H.; Ko, H.J.; Ko, C.S. A genetic algorithm approach to developing the multi-echelon reverse logistics network for product returns. Omega 2006, 34, 56-69. [CrossRef]

27. Cruz-Rivera, R.; Ertel, J. Reverse logistics network design for the collection of end-of-life vehicles in Mexico. Eur. J. Op. Res. 2009, 196, 930-939. [CrossRef]

28. Alumur, S.A.; Nickel, S.; Saldanha-da-Gama, F.; Verter, V. Multi-period reverse logistics network design. Eur. J. Op. Res. 2012, 220, 67-78. [CrossRef]

29. Govindan, K.; Soleimani, H.; Kannan, D. Reverse logistics and closed-loop supply chain: A comprehensive review to explore the future. Eur. J. Op. Res. 2015, 240, 603-626. [CrossRef]

30. Listeş, O.; Dekker, R. A stochastic approach to a case study for product recovery network design. Eur. J. Op. Res. 2005, 160, 268-287. [CrossRef]

31. Salema, G.M.I.; Barbosa-Povoa, A.P.; Novais, A.Q. An optimization model for the design of a capacitated multi-product reverse logistics network with uncertainty. Eur. J. Op. Res. 2007, 179, 1063-1077. [CrossRef]

32. Moghaddam, K.S. Fuzzy multi-objective model for supplier selection and order allocation in reverse logistics systems under supply and demand uncertainty. Expert Syst. Appl. 2015, 42, 6237-6254. [CrossRef]

33. Daaboul, J.; Le Duigou, J.; Penciuc, D.; Eynard, B. An integrated closed-loop product lifecycle management approach for reverse logistics design. Prod. Plan. Control 2016, 27, 1062-1077. [CrossRef]

34. Li, Y.; Kannan, D.; Jha, P.; Garg, K.; Darbari, J.; Agarwal, N. Design of a multi echelon product recovery embeded reverse logistics network for multi products and multi periods. Ann. Op. Res. 2018, 3, 1-22. [CrossRef]

35. Kara, S.S.; Onut, S. A stochastic optimization approach for paper recycling reverse logistics network design under uncertainty. Int. J. Environ. Sci. Technol. 2010, 7, 717-730. [CrossRef]

36. Alshamsi, A.; Diabat, A. A reverse logistics network design. J. Manuf. Syst. 2015, 37, 589-598. [CrossRef]

37. Choudhary, A.; Sarkar, S.; Settur, S.; Tiwari, M. A carbon market sensitive optimization model for integrated forward-reverse logistics. Int. J. Prod. Econ. 2015, 164, 433-444. [CrossRef]

38. Mafakheri, F.; Nasiri, F. Revenue sharing coordination in reverse logistics. J. Clean. Prod. 2013, 59, 185-196. [CrossRef]

39. Zakeri, A.; Dehghanian, F.; Fahimnia, B.; Sarkis, J. Carbon pricing versus emissions trading: A supply chain planning perspective. Int. J. Prod. Econ. 2015, 164, 197-205. [CrossRef]

40. Kannan, D.; Alrefaei, M.; Govindan, K.; Yong, G. A carbon footprint based reverse logistics network design model. Resour. Conserv. Recycl. 2012, 67, 75-79. [CrossRef]

41. Diabat, A.; Abdallah, T.; Al-Refaie, A.; Svetinovic, D.; Govindan, K. Strategic closed-loop facility location problem with carbon market trading. IEEE Trans. Eng. Manag. 2013, 60, 398-408. [CrossRef]

42. Guo, J.; Wang, X.; Fan, S.; Gen, M. Forward and reverse logistics network and route planning under the environment of low-carbon emissions: A case study of Shanghai fresh food E-commerce enterprises. Comput. Ind. Eng. 2017, 106, 351-360. [CrossRef]

43. Xiao, Z.; Sun, J.; Shu, W.; Wang, T. Location-allocation problem of reverse logistics for end-of-life vehicles based on the measurement of carbon emissions. Comput. Ind. Eng. 2019, 127, 169-181. [CrossRef]

44. Mikulčić, H.; Klemeš, J.J.; Vujanović, M.; Urbaniec, K.; Duić, N. Reducing greenhouse gasses emissions by fostering the deployment of alternative raw materials and energy sources in the cleaner cement manufacturing process. J. Clean. Prod. 2016, 136, 119-132. [CrossRef] 
45. Soysal, M.; Bloemhof-Ruwaard, J.; van der Vorst, J. Modelling food logistics networks with emission considerations: The case of an international beef supply chain. Int. J. Prod. Econ. 2014, 152, 57-70. [CrossRef]

46. Hickman, J.; Hassel, D.; Joumard, R.; Samaras, Z.; Sorenson, S. Methodology for Calculating Transport Emissions and Energy Consumption; Transport Research Labotory: Crowthorne, UK, 1999.

47. Der Vorst, V.G.J.; Tromp, S.-O.; Zee, D.-J.v.d. Simulation modelling for food supply chain redesign; integrated decision making on product quality, sustainability and logistics. Int. J. Prod. Res. 2009, 47, 6611-6631. [CrossRef]

48. Bing, X.; Bloemhof-Ruwaard, J.; Chaabane, A.; van der Vorst, J. Global reverse supply chain redesign for household plastic waste under the emission trading scheme. J. Clean. Prod. 2015, 103, 28-39. [CrossRef]

49. Naraharisetti, P.; Karimi, I. Supply chain redesign and new process introduction in multipurpose plants. Chem. Eng. Sci. 2010, 65, 2596-2607. [CrossRef]

50. Atasu, A.; Guide, V.D.R., Jr.; van Wassenhove, L.N. Product reuse economics in closed-loop supply chain research. Prod. Op. Manag. 2008, 17, 483-496. [CrossRef]

51. Benedito, E.; Corominas, A. Optimal manufacturing policy in a reverse logistics system with dependent stochastic returns and limited capacities. Int. J. Prod. Res. 2013, 51, 189-201. [CrossRef]

52. Feitó-Cespón, M.; Sarache, W.; Piedra-Jimenez, F.; Cespón-Castro, R. Redesign of a sustainable reverse supply chain under uncertainty: A case study. J. Clean. Prod. 2017, 151, 206-217. [CrossRef]

53. Saha, D.M.A. Low-Carbon Infrastructure Private Participation in Infrastructure (PPI): 2002 to H1 2017 (English); World Bank Group: Washington, DC, USA, 2017.

54. Vella, H. Green IT Can Champion Cuts in Carbon Emissions. Available online: https://www.raconteur.net/ hr/green-tech-carbon-emissions (accessed on 11 May 2019).

55. Pishvaee, S.M.; Farahani, R.Z.; Dullaert, W. A memetic algorithm for bi-objective integrated forward/reverse logistics network design. Comput. Op. Res. 2010, 37, 1100-1112. [CrossRef]

56. Andersson, J.; Rudberg, M. Supply chain redesign employing advanced planning systems. In Advances in Production Management Systems; Springer: Boston, MA, USA, 2007; pp. 3-10.

57. Dai, F.L.; Wang, X.F. Research on mixed intelligent arithmetic of reuse reverse logistics centers' location model. Adv. Mater. Res. 2014, 945, 3246-3251. [CrossRef]

58. Fishburn, P.C. Letter to the editor-Additive utilities with incomplete product sets: Application to priorities and assignments. Op. Res. 1967, 15, 537-542. [CrossRef]

59. Manopiniwes, W.; Irohara, T. Stochastic optimisation model for integrated decisions on relief supply chains: Preparedness for disaster response. Int. J. Prod. Res. 2017, 55, 979-996. [CrossRef]

60. Rath, S.; Gendreau, M.; Gutjahr, W.J. Bi-objective stochastic programming models for determining depot locations in disaster relief operations. Int. Trans. Op. Res. 2016, 23, 997-1023. [CrossRef]

61. Yang, X.-S.; Karamanoglu, M.; He, X. Multi-objective flower algorithm for optimization. Procedia Comput. Sci. 2013, 18, 861-868. [CrossRef]

(C) 2019 by the author. Licensee MDPI, Basel, Switzerland. This article is an open access article distributed under the terms and conditions of the Creative Commons Attribution (CC BY) license (http://creativecommons.org/licenses/by/4.0/). 